\title{
Non-stoichiometry, structure and properties of proton-conducting
}

\author{
perovskite oxides \\ Shuangbin $\mathrm{Li}^{1}$ and John T. S. Irvine ${ }^{1, *}$ \\ 1 School of Chemistry, University of St Andrews, KY16 9ST, United Kingdom
}

\begin{abstract}
The demand for clean and sustainable energy has garnered great interest in new energy materials. Among them, high temperature proton-conducting perovskite oxides are, or can be widely used in clean energy applications (including fuel cells, electrochemical reactors, solid-state separators and supports of catalytic components via various reduction and oxidation reactions) in the intermediate temperature range. The control of defect chemistry is the main strategy to fine tune properties for these applications. This review provides a critical discussion about non-stoichiometry-structure-property relation in terms of structure distortions by intrinsic octahedral titling and extrinsic acceptor doping, chemical stability, hydration behavior, transport properties, and catalytic effects in some typical classes of proton conducting perovskites and perovskite-related derivatives. A good understanding of A-site and B-site nonstoichiometry is also given to allow the perovskite structure with desired properties.
\end{abstract}

\section{Introduction}

Oxide ion conductors are considered as conventional separator materials in solid oxide fuel cells (SOFCs). Despite current well-established SOFC technology, operation over a relatively high temperature range (typically $700-1000{ }^{\circ} \mathrm{C}$ ) is still the major challenge in terms of practical considerations, e.g., materials choice and compatibility, thermal and redox cycles, long-term reliability and cost effectiveness [1-4]. Protonconducting oxides are expected to be suitable alternatives at intermediate or lower temperatures due to the substantial advantages. The proton transport dominates the conduction mechanism under saturated water vapor atmosphere and in the temperature regime of $300-700{ }^{\circ} \mathrm{C}[5,6]$, exhibiting the activation energy of $0.4-0.6 \mathrm{eV}$ lower than that of oxide ion conductors (0.6-1.2 eV) [7]. Compared to SOFCs, the arrangement of 
protonic ceramic fuel cells (PCFCs) allows water production at the air electrode to avoid the dilution of fuel and thus enable more fuel utilization. When PCFCs are operated in reverse, i.e., protonic ceramic electrolysis cells (PCECs), water splitting at the air electrode can alleviate the Ni coarsening and oxidation at the fuel electrode. In the meantime, pure and dry hydrogen produced at the fuel electrode makes a less complicated system to storage hydrogen. Besides as the solid electrolyte for fuel cells and electrolysis cells, proton-conducting ceramics have great potential to serve as supports or reactors in many fields (e.g., ammonia synthesis [8, 9], natural gas upgrading[3, 10], syngas production [11-13], hydrogen pumps [14, 15], hydrogen sensors $[16,17])$.

In the past decades, considerable attempts have been devoted to developing protonconduction oxides since Iwahara and colleagues discovered $\mathrm{A}^{2+} \mathrm{B}^{4+} \mathrm{O}_{3}$ perovskites $\left(\mathrm{BaCeO}_{3}\right.$ and $\mathrm{BaZrO}_{3}$ based families) with appreciable properties [18]. Disordered, and derivative perovskites also have been well-developed in recent years, including $\mathrm{A}^{1+} \mathrm{B}^{5+} \mathrm{O}_{3}\left(\mathrm{KTaO}_{3}\right)$ [19], $\mathrm{A}^{3+} \mathrm{B}^{3+} \mathrm{O}_{3}\left(\mathrm{LaInO}_{3}\right)$ [20], $\mathrm{A}_{2} \mathrm{BB}^{\prime} \mathrm{O}_{5}\left(\mathrm{Ba}_{2} \mathrm{In}_{2} \mathrm{O}_{5}\right)$ [21], $\mathrm{A}_{2}\left(\mathrm{BB}^{\prime}\right) \mathrm{O}_{6}$ $\left(\mathrm{Sr}_{2}(\mathrm{ScNb}) \mathrm{O}_{6}\right)[22]$ and $\mathrm{A}_{3}\left(\mathrm{BB}_{2}^{\prime}\right) \mathrm{O}_{9}\left(\mathrm{Ba}_{3}\left(\mathrm{CaNb}_{2}\right) \mathrm{O}_{9}\right)[23,24]$. In all these cases, proton $\left(\mathrm{H}^{+}\right)$is not an essential constituent in the perovskite structure due to the extremely small proton without electron shell. Instead, a bare proton bonding to a lattice oxygen, denoting proton defect $\left(\mathrm{OH}_{\mathrm{O}}^{\bullet}\right)$, could accommodate the lattice site that fulfills the requirements for proton transport. According to the Grotthuss type mechanism explained by Kreuer [25], a proton migrates from one site to another site in the lattice via trapping and hopping between neighboring $\mathrm{O}$ sites under saturated water pressure and lower temperatures, in which mobile protons are incorporated into the lattices by water dissociation filling in oxygen vacancy sites (hydration reaction), as described in Eq.1.

$$
\mathrm{H}_{2} \mathrm{O}(\mathrm{g})+\mathrm{V}_{\mathrm{O}}^{\bullet \bullet}+\mathrm{O}_{\mathrm{O}}^{\times} \rightarrow 2 \mathrm{OH}_{\mathrm{O}}^{\bullet}
$$

Thus, Oxygen vacancies are the necessities for proton transport in proton-conducting oxides, strongly associated with the concentrations of oxygen ions, protons and electrons/ holes charge carriers in different conditions. In case of $\mathrm{BaCeO}_{3}$, for example, 
oxygen vacancies can either be created by intrinsic octahedral titling [26] or extrinsic acceptor doping [27] (e.g., $\mathrm{Y}^{3+}, \mathrm{Yb}^{3+}, \mathrm{Gd}^{3+}, \mathrm{Sm}^{3+}, \mathrm{Nd}^{3+}$, giving formula: $\mathrm{BaCe}_{1-\mathrm{x}} \mathrm{M}_{\mathrm{x}} \mathrm{O}_{3-}$ $\mathrm{x} / 2$ ) to stabilize $\mathrm{Ce}^{4+}$ valence state. The charge neutrality can be compensated in Eq.2. The substitution of trivalent cations for the Ba site (such as $\mathrm{La}^{3+}$ and $\mathrm{Sm}^{3+}$ ), however, gives rise to a decrease of oxygen vacancy concentration (Eq. 3), thereby causing the suppression of proton transport in the lattice.

$$
\begin{gathered}
2 \mathrm{Ce}_{\mathrm{Ce}}^{\times}+\mathrm{O}_{\mathrm{O}}^{\times}+\mathrm{M}_{2} \mathrm{O}_{3} \rightarrow 2 \mathrm{M}_{\mathrm{Ce}}^{\prime}+\mathrm{V}_{\mathrm{O}}^{\bullet \bullet}+2 \mathrm{CeO}_{2} \\
2 \mathrm{Ba}_{\mathrm{Ba}}^{\times}+\mathrm{M}_{2} \mathrm{O}_{3}+\mathrm{V}_{\mathrm{O}}^{\bullet \bullet} \rightarrow 2 \mathrm{M}_{\mathrm{Ba}}^{\bullet}+\mathrm{O}_{\mathrm{O}}^{\times}+2 \mathrm{BaO}
\end{gathered}
$$

Very recently, an electron doping strategy [28] was employed to introduce proton defects into $\mathrm{SmNiO}_{3}$ perovskite via hydrogenation in the absence of oxygen vacancies (Eq.4), which may be ascribed to the strong electron-lattice coupling in the presence of a Coulomb gap. Though this new finding probably implies the unconventional proton incorporation and diffusion in perovskite oxides, the underlying mechanisms require further investigation in great detail.

$$
\mathrm{Ni}^{3+}+\mathrm{O}_{\mathrm{O}}^{\times}+1 / 2 \mathrm{H}_{2} \rightarrow \mathrm{Ni}^{2+}+\mathrm{OH}_{\mathrm{O}}^{\bullet}
$$

Even though good progress has also been made in non-perovskite oxides (e.g., pyrochlore-type structure [29] and fergusonite-type structure [30]), current and nearterm research is still geared toward perovskite oxides $\left(\mathrm{BaCeO}_{3}\right.$ and $\mathrm{BaZrO}_{3}$ based systems) due to their superior proton conductivity [3]. A good understanding of proton transport mechanism, synthesis, and applications has been reviewed by Kreuer et al. [1, 31], Medvedev et al. [32, 33], Marrony et al. [34], and other authors [3, 35-37] in this field. Nonetheless, the impact of defect chemistry on structures and properties of perovskite proton conductors is not fully understood and the relation between nonstoichiometry, structure and property requires more discussion. This review aims to establish a clear non-stoichiometry--structure-property relationship in perovskites, providing a critical strategy for rational design and tailoring of new proton-conducting oxides. In order to simplify text proton conductors should be assumed to be the cerateand zirconate-based perovskite oxides, unless stated otherwise. 


\section{Crystal structure of $\mathrm{A}^{2+} \mathrm{B}^{4+} \mathrm{O}_{3}$ perovskite}

Proton-conducting perovskite oxides comprise a large family of A- and B-site doped compositions, accompanied with cation and anion non-stoichiometries. Before discussing them, the basic knowledge of simple perovskite structure should first be understood. A typical $\mathrm{ABO}_{3}$ perovskite consists of large-sized 12-coordinated $\mathrm{A}^{2+}$ cations occupying the center of a cubic cell (Fig.1(a)), while small-sized 6-coordinated $\mathrm{B}^{4+}$ cations are located at the corner of the unit. The structure also can be represented by 8 cages of corner-shared $\mathrm{BO}_{6}$ octahedral centering in $\mathrm{B}^{4+}$ cation to form cubooctahedral cavities (Fig.1(b)) [38]. However, most of them deviate from the ideal cubic perovskite structure (space group, $P m \overline{3} m$ ) and show different types of disordered structures. Goldschmidt tolerance factor, $t$, has been widely accepted as a criterion for perovskite deviation, measured by the mismatch between the average equilibrium A-O and $\mathrm{B}-\mathrm{O}$ bond lengths:

$$
t=\frac{r_{A}+r_{O}}{\sqrt{2}\left(r_{B}+r_{O}\right)}
$$

Where $r_{\mathrm{A}}, r_{\mathrm{B}}$ and $r_{\mathrm{O}}$ is the ionic radius of $\mathrm{A}, \mathrm{B}$ and $\mathrm{O}$ ions, respectively. Cubic symmetry is generally obtained in the range of $0.95 \leq t \leq 1.04$. The value of $t=1$, the ideal cubic perovskite, is simply calculated from the relationship between the length of face diagonal and the edge of the cube. If $t>1$, tensile A-O bonds and compressive B$\mathrm{O}$ bonds result in the displacement of the $\mathrm{B}$-site cation within the $\mathrm{BO}_{6}$ octahedral or even form hexagonal structure [39].

(a)

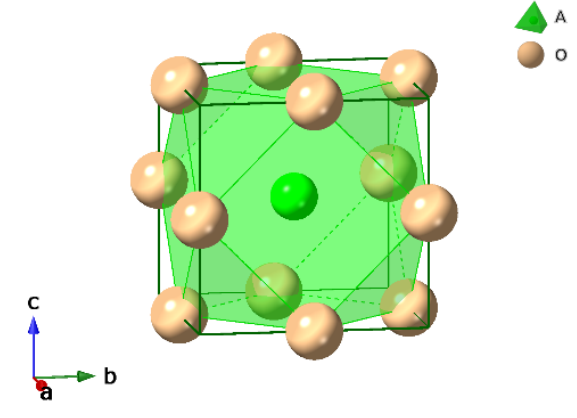

(b)

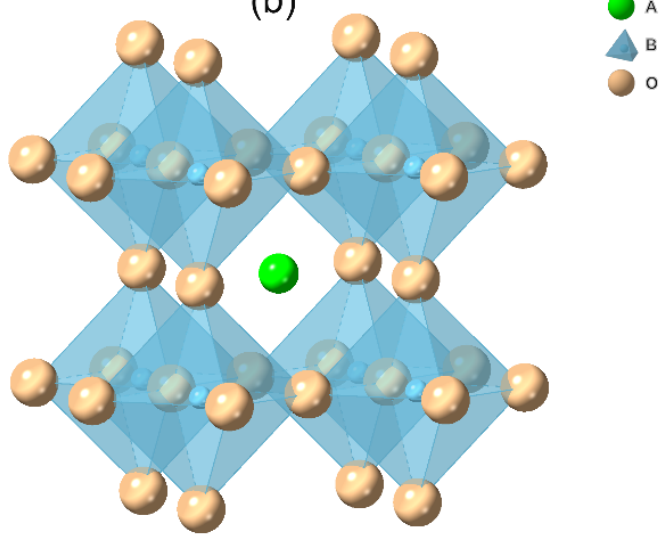

Fig.1. Crystal structure of ideal cubic perovskite: (a) 12-fold coordination of the A-site cation, (b) 8 cages of corner-shared $\mathrm{BO}_{6}$ octahedral. 
The factor $t<1$ indicates the cation at the A site is small relative to the cage of the surrounding oxygen ions and $\mathrm{BO}_{6}$ octahedra, enabling the shortening of A-O bonds. In this case, the octahedral tilting (including in-phase and antiphase tilt) is able to retain the perovskite structure but with lower symmetry. A decrease in the angle of B-O-B bonds from $180^{\circ}$ and in the coordination number of the A-site cation from 12 to $8-10$ are two possible observations derived from octahedral tilting [38]. Note that the degree of octahedral titling generally decreases with increasing temperature, i.e., the crystal symmetry is high at high temperatures and defects in perovskites can be created by control of structure disordering or non-stoichiometry. As a result, the symmetric perovskite structure tends to reduce in a highly distorted symmetry (e.g., orthorhombic, tetragonal, trigonal structures) with decreasing the tolerance factor $(t)$. Until $t<0.75$, the perovskite structure collapses and instead the ilmenite structure forms due to the similar size of A-site and B-site cations.

Here we exemplify $\mathrm{BaCeO}_{3}$ as a stoichiometric perovskite $\left(\mathrm{ABO}_{3}\right)(t=0.94)$ to dictate the evolution of symmetry structures. Due to the nature of octahedral tilting like $\mathrm{GdFeO}_{3}$-type perovskite at lower temperatures, the Pbnm settings with $\sqrt{2} \mathrm{a}_{\mathrm{p}} \times \sqrt{2} \mathrm{a}_{\mathrm{p}} \times 2 \mathrm{a}_{\mathrm{p}}$

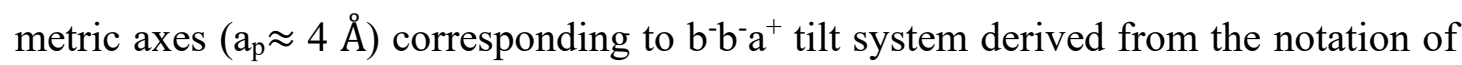
Glazerunit [40, 41], are employed to demonstrate orthorhombic distortion [42, 43]. Octahedral rotation towards $[100]_{\mathrm{p}},[010]_{\mathrm{p}},[001]_{\mathrm{p}}$ directions from primitive cubic perovskite lead to two antiphase $\left([100]_{\mathrm{p}},[010]_{\mathrm{p}}\right)$ and one in-phase tilting ( $[001]_{\mathrm{p}}$, caxis in Pbnm). Both antiphase rotation behaviors could be supposed to be a net titling towards $[110]_{\mathrm{p}}$ direction (b-axis in Pbnm). Thus, two possible deformation schemes were proposed: a small variation from the shift of an $\mathrm{O}$ site towards a $\mathrm{B}$ site, as expressed by

$$
\gamma_{\mathrm{BO}}=\left(\mathrm{B}-\mathrm{O}_{\text {long }}\right) /\left(\mathrm{B}-\mathrm{O}_{\text {short }}\right)
$$

and a distortion in basal plane edge lengths,

$$
\gamma_{\mathrm{O} 2-\mathrm{O} 2}=\left(\mathrm{O} 2-\mathrm{O} 2_{\text {long }}\right) /\left(\mathrm{O} 2-\mathrm{O} 2_{\text {short }}\right)
$$

Knight et al. [44, 45] explicated crystallography of $\mathrm{BaCeO}_{3}$ polymorphs from high-resolution neutron power diffraction data by using a setting of space group No.62, 
Pmcn ( $\mathrm{a}^{+} \mathrm{b}^{-} \mathrm{b}^{-}$system, axial setting $2 \mathrm{a}_{\mathrm{p}} \times \sqrt{2} \mathrm{a}_{\mathrm{p}} \times \sqrt{2} \mathrm{a}_{\mathrm{p}}$ ). The results imply that the unit cell is orthorhombic (Pmcn, $\left.\mathrm{a}^{+} \mathrm{b}^{-} \mathrm{b}^{-}\right)$at room temperature, and undergoes three phase transitions upon heating: firstly losing an in-phase tilt to body-centered orthorhombic (Incn, $\left.\mathrm{a}^{\mathrm{o}} \mathrm{b}^{-} \mathrm{b}^{-}\right)$at about $300{ }^{\circ} \mathrm{C}$, then gaining a tilt to rhombohedral $\left(F-\overline{3} 2 / n, \mathrm{a}^{-} \mathrm{a}^{-} \mathrm{a}^{-}\right)$at about $400{ }^{\circ} \mathrm{C}$, and finally to cubic aristotype $\left(P m \overline{3} m, \mathrm{a}^{\circ} \mathrm{a}^{\circ} \mathrm{a}^{\circ}\right)$ at approximately $900{ }^{\circ} \mathrm{C}$ $[45,46]$. The unusual phase transformation from Incn to $F-\overline{3} 2 / n$ was also reported to increase the octahedral titling with ramping temperature, which is contradictory to general concept, as presented in Fig.2. Moreover, this phase transition is considered to be first order due to the absence of group-subgroup relationship, along with approximately $0.5 \%$ volume change, and the rest belongs to second order transitions [47]. To avoid misleading the use of space group, it should be mentioned that the space groups of Pmcn, Incn, $F-\overline{3} 2 / n$ and $P m \overline{3} m$ determined by Knight are corresponding to the standard settings of Pnma, Imma, $R \overline{3} c$ and $P m \overline{3} m$ space groups, respectively.
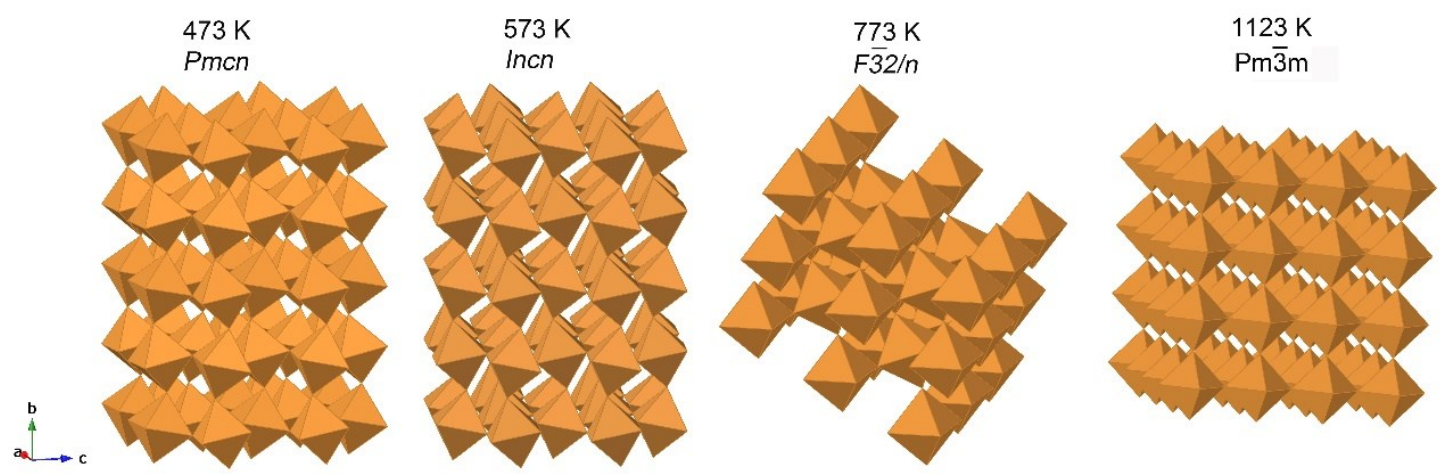

Fig.2. Schematic of $\mathrm{BaCeO}_{3}$ phase transitions.

Compared to multiple structural phase transitions in $\mathrm{BaCeO}_{3}$, diffraction techniques indicate the cubic phase of $\mathrm{BaZrO}_{3}$ perovskite remains down to $\mathrm{T}=0 \mathrm{~K}$, as sufficient quantum fluctuations in $\mathrm{BaZrO}_{3}$ can suppress the transition [48, 49]. While several DFT calculations imply a very weak out-of-phase antiferrodistortive transition in $\mathrm{BaZrO}_{3}$ associated with rigid rotations of the $\mathrm{ZrO}_{6}$ oxygen octahedra. This is primarily due to different exchange-correlation functionals used in the calculations. Indeed, $\mathrm{BaZrO}_{3}$ with a tolerance factor of 1.01, a bit larger than unity [50], has the lowest distortion and largest cell volume among those proton-conducting perovskites, which is strongly related to the chemical stability and conductivity. 
In addition, $\mathrm{BaCeO}_{3}$ also shows superior conductivity than $\mathrm{SrCeO}_{3}$ in the presence of the phase transition at $c a .300{ }^{\circ} \mathrm{C}$, with a remarkable increase in octahedral titling occurs from orthorhombic to rhombohedral phase. While $\mathrm{SrCeO}_{3}$ has no structure phase change until the temperature up to $1000{ }^{\circ} \mathrm{C}$ [51]. The distinct difference is probably ascribed to the smaller ion radii of $\mathrm{Sr}^{2+}(1.26 \AA)$ than that of $\mathrm{Ba}^{2+}(1.42 \AA)$, which results in a strong strain from large tilting of $\mathrm{CeO}_{6}$ octahedra in $\mathrm{SrCeO}_{3}$.

\section{Defect chemistry influence on structure}

Pristine $\mathrm{ABO}_{3}$ perovskites $(\mathrm{A}=\mathrm{Ca}, \mathrm{Ba}, \mathrm{Sr} ; \mathrm{B}=\mathrm{Ce}, \mathrm{Zr})$ show poor proton conduction due to low intrinsic oxygen vacancies. In this regard, defect chemistry in perovskite oxides associated with cation and oxygen non-stoichiometries, plays a crucial role on microstructures and cell parameters, which in turn substantially affect proton transport properties. In this section we place an emphasis on the impact of defect chemistry on structural distortion and parameters, and discuss a little about correlated proton conductivity. Some Kröger-Vink notations are used to interpret these variations.

\subsection{A-site non-stoichiometry}

Undoped $\mathrm{BaCeO}_{3}$ may accommodate $\mathrm{Ba}$ deficiency since high temperature sintering can exacerbate $\mathrm{Ba}$ evaporation, as determined by Shima and Haile [52]. Meanwhile, small $\mathrm{Ba}$ loss at high temperatures enables the formation of an A-sitecation deficient perovskite and, however, can facilitate the partial decomposition of perovskite structure [53]. As a result, measurable quantities of $\mathrm{CeO}_{2}$ segregate from $\mathrm{Ba}_{\mathrm{x}} \mathrm{CeO}_{3-\delta}(0.96 \leq x<1$, even with $1 \mathrm{~mol} \% \mathrm{Ba}$ deficiency), rendering an unstable perovskite phase. A similar study investigated by Ma et al. [54] suggested that compositions with $0.95<x \leq 1.10$ showed a single orthorhombic perovskite, while the composition with $\mathrm{x} \leq 0.95$ showed the mixed phases of perovskite and $\mathrm{CeO}_{2}$. A slight deviation of results can be ascribed to different fabrication and annealing processing, leading to subtle variations in the chemistry or microstructure. One can consider $\mathrm{Ba}$ deficiency corresponds to Ce excess relative to stoichiometric composition such that four possible defect reactions can be provided to explain $\mathrm{CeO}_{2}$ segregation in undoped 
compositions. Eq. 8-10 are not taken into account, because in Eq.8 highly charged Ce interstitials and $\mathrm{O}$ interstitials are unfavorable due to a decrease in unit cell volume with increasing Ba deficiency, as shown in Fig. 3(b); In Eq.9 the ion radius of $\mathrm{Ba}^{2+}$ is too big and thus undoped $\mathrm{BaCeO}_{3}$ is unlikely to accommodate both barium and oxygen vacancies simultaneously; In Eq.10 O interstitials are impossible in oxygen nonstoichiometric compositions. Thus, the alternative approach tends to the slightly partial decomposition of barium cerate to $\mathrm{BaO}$ and $\mathrm{CeO}_{2}$, as given in Eq.11.

$$
\begin{gathered}
\mathrm{CeO}_{2} \rightarrow \mathrm{Ce}_{\mathrm{i}}^{\square m}+\angle \mathrm{O}_{\mathrm{i}}^{\prime \prime} \\
\mathrm{CeO}_{2} \rightarrow \mathrm{Ce}_{\mathrm{Ce}}+2 \mathrm{O}_{\mathrm{O}}+\mathrm{V}_{\mathrm{Ba}}^{\prime \prime}+\mathrm{V}_{\mathrm{O}}^{\square} \\
2 \mathrm{CeO}_{2} \rightarrow \mathrm{Ce}_{\mathrm{Ce}}+\mathrm{Ce}_{\mathrm{Ba}}^{\square}+\mathrm{O}_{\mathrm{O}}+\mathrm{O}_{\mathrm{i}}^{\prime \prime} \\
\mathrm{Ba}_{\mathrm{Ba}}^{\times}+\mathrm{Ce}_{\mathrm{Ce}}^{\times}+3 \mathrm{O}_{\mathrm{O}}^{\times} \rightarrow \mathrm{CeO}_{2}+2 \mathrm{BaO} \uparrow \\
2 \mathrm{BaO} \rightarrow \mathrm{Ba}_{\mathrm{Ba}}+\mathrm{Ba}_{\mathrm{Ce}}^{\prime \prime}+2 \mathrm{O}_{\mathrm{O}}+2 \mathrm{~V}_{\mathrm{O}}^{\bullet}
\end{gathered}
$$

Analogous to $\mathrm{Ba}$-deficient $\mathrm{BaCeO}_{3}$, undoped $\mathrm{BaZrO}_{3}$ is also unable to tolerate $\mathrm{Ba}$ deficiency [55]. Nevertheless, small amount of excess Ba can occupy the perovskite structure of both undoped $\mathrm{BaCeO}_{3}$ and $\mathrm{BaZrO}_{3}$, as shown in Fig.3(a). Despite the great size mismatching of 6-coordinated $\mathrm{Ba}^{2+}(1.35 \AA)$ and $\mathrm{Ce}^{4+}(0.87 \AA)$, a small portion of excess $\mathrm{BaO}$ is expected to incorporate into the $\mathrm{B}$ site, which is similar to the substitution of trivalent dopants (such as $\mathrm{Y}, \mathrm{Yb}$ and $\mathrm{Gd}$ ). Such replacement of Ce with $\mathrm{Ba}$ is verified by an increase of unit cell volume with increasing Ba concertation (Fig. 3b). Also, the incorporation of $\mathrm{BaO}$ increases the concentration of oxygen vacancies via Eq.12 and thereby exhibits higher conductivity compared to stoichiometric composition. Alternatively, most of excess $\mathrm{Ba}$ is assumed to accumulate in grain boundary regions and promote grain growth and densification during high temperature sintering, which also accounts for the enhanced conductivity [56]. 
(a)

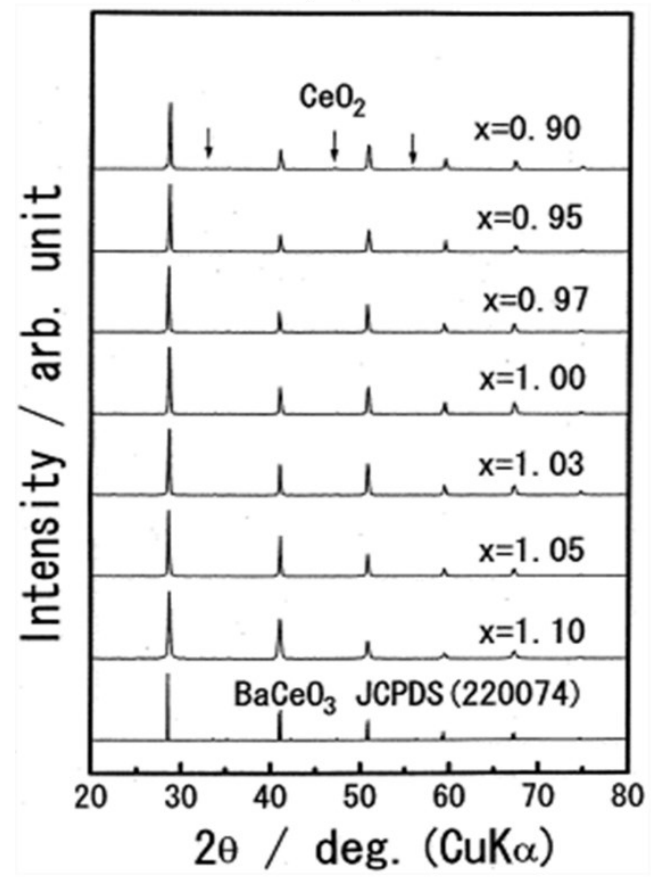

(b)

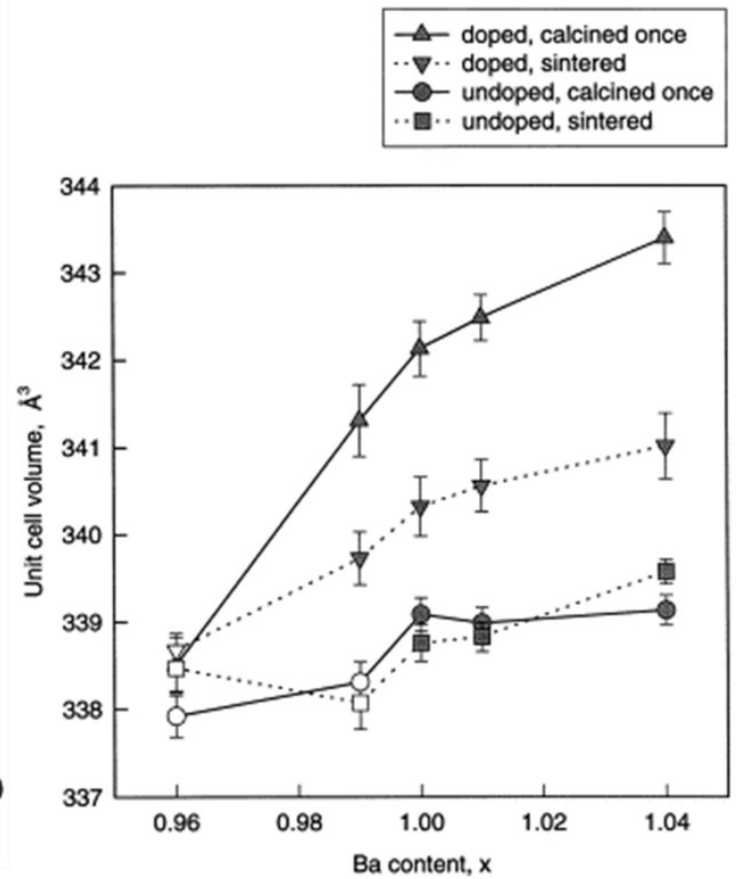

Fig. 3. (a) $\mathrm{XRD}$ patterns of $\mathrm{Ba}_{x} \mathrm{CeO}_{3-\delta}(0.96 \leq x \leq 1.1)$ at room temperature [54]. (b) Unit cell volumes of $\mathrm{Ba}_{x} \mathrm{CeO}_{3-\delta}$ and $\mathrm{Ba}_{x} \mathrm{Ce}_{0.85} \mathrm{Gd}_{0.15} \mathrm{O}_{3-\delta}(0.96 \leq x \leq 1.04)$ compositions upon calcining $\left(1300{ }^{\circ} \mathrm{C}\right)$ and sintering $\left(1600^{\circ} \mathrm{C}\right)[52]$.

The fluorite phase, however, may emerge in the non-stoichiometry of doped $\mathrm{BaCeO}_{3}$ and $\mathrm{BaZrO}_{3}$ compositions ( $\mathrm{Ba}$ deficiency and $\mathrm{Ba}$ excess) depending on the nature of acceptor dopant and its concentration, as determined in $\mathrm{Ba}_{x} \mathrm{Zr}_{0.85} \mathrm{Y}_{0.15} \mathrm{O}_{3-\delta}(x=$ 0.96-1.04) [55], $\mathrm{Ba}_{x} \mathrm{Ce}_{0.85} \mathrm{M}_{0.15} \mathrm{O}_{3-\delta}(x=0.85-1.20 ; \mathrm{M}=\mathrm{La}, \mathrm{Sm}, \mathrm{Nd}, \mathrm{Gd}, \mathrm{Yb})[57,58]$, $\mathrm{Ba}_{x} \mathrm{Ce}_{0.50} \mathrm{Zr}_{0.40} \mathrm{Y}_{0.10} \mathrm{O}_{3-\delta}(x=0.95-1.05)$ [59], $\mathrm{Ba}_{x} \mathrm{Ce}_{0.7} \mathrm{Zr}_{0.1} \mathrm{Y}_{0.1} \mathrm{Yb}_{0.1} \mathrm{O}_{3-\delta}(x=0.9-1.1)$ [60]. This means that B-site acceptor doping is capable of accommodating A-site deficiencies and excess, even with 4 mol\% nominal Ba deficiencies and excess in doped compositions. In this scenario, dopants at the B site appear to partially incorporate into the A site so that the dopant partitioning could stabilize the perovskite in compensation for Ba deficiency (or Ba loss) and result in the decrease in cell constant with increasing deficiency concentration (in Fig. 3b). Such a cross-substitution approach will be discussed in section 3.3. In addition, Yamazaki et al. [61] observed that the measured stoichiometries of Ba-deficient $\mathrm{Ba}_{1-x} \mathrm{Zr}_{0.8} \mathrm{Y}_{0.2} \mathrm{O}_{3-\delta}$ compositions were slightly smaller by ca. 0.02 than nominal values, despite that measures were taken to prevent $\mathrm{Ba}$ evaporation. If $x$ is further increased, the cubic phase could hold up to the Ba deficiency 
of 0.06 and then the zirconium-doped yttrium phase emerged in the Ba-deficient range of $0.08 \leq x \leq 0.2$. If $x$ increases at a higher level from 0.3 to 0.4 , the yttrium-doped zirconia phase appeared, the lattice constant of which is comparable to that of undoped barium zirconia, suggesting a successive segregation of yttria with increasing $x$. Therefore, it is very important to control the stoichiometry of cations and dopants to obtain desirable perovskite structure and proton conduction. In contrast to $\mathrm{Ba}$ nonstoichiometry, $\mathrm{Sr}_{1+{ }_{x}} \mathrm{CeO}_{3-\delta}(-0.02 \leqslant x \leqslant 0.04)$ seemed to be a single crystal structure and $\mathrm{Sr}$ content was more coincident with the nominal stoichiometry, as determined by ICP-AES [62]. The examination of strontium deficiency indicated that $\mathrm{Sr}_{1-}$ ${ }_{\mathrm{x}} \mathrm{Ce}_{0.9} \mathrm{Yb}_{0.1} \mathrm{O}_{3-\delta}$ compositions in the range of $0 \leqslant x \leqslant 0.06$ showed the orthorhombic structure, in which in-phase and out-phase tilting in the superlattice were confirmed by SEAD, based on complex octahedral tilting using the $\mathrm{a}^{-} \mathrm{b}^{+} \mathrm{a}^{-}$settings (space group Pnma). And this type of defect was further confirmed by twinning and anti-phase boundaries along [010]p zone axis in HRTEM image [63].

Meanwhile, Kruth et al. [64] found anomalous structural variations in refined unit cell parameters when in comparing three A-site-deficient cerate systems, including $\mathrm{Ba}_{1-}$ ${ }_{\delta} \mathrm{Ce}_{0.9} \mathrm{Y}_{0.1} \mathrm{O}_{2.95-\delta}, \mathrm{Sr}_{1-\delta} \mathrm{Ce}_{0.9} \mathrm{Gd}_{0.1} \mathrm{O}_{2.95-\delta}$, and $\mathrm{Ba}_{1-\delta} \mathrm{Ce}_{0.9} \mathrm{Yb}_{0.1} \mathrm{O}_{2.95-\delta}$, as presented in Fig.4. Compared to doped barium cerate, doped strontium cerate showed greater orthorhombic distortion, despite different acceptor dopant incorporation. In all three cases, the anomalous variation of structure parameters occurred close to an oxygen stoichiometry of 2.94, but with some extent of deviation from Vegard's law. In this law, the unit cell volume should vary in linearly with composition variations over the entire range of solid solutions. Such nonsystematic behaviors in Fig. 4, nonetheless, are probably induced by lower crystal symmetry due to the size mismatch of dopants at the $\mathrm{B}$ site. $\mathrm{BaCe}_{0.9} \mathrm{Y}_{0.1} \mathrm{O}_{2.95}$ with tolerance factor of 0.938 , for example, is more slightly distorted with respect to $t=0.940$ for $\mathrm{BaCeO}_{3}$. Another possible assumption is that the high concentration of oxygen vacancies facilitates the oxygen vacancies ordering in local structure, forming a different superstructure at certain doping levels [65]. Further evidence indicates that this abnormal change not only occurs in A-site-deficient 
situation, but also in B-site-substitution and dual-doping cases. A reasonable scenario is the formation of defect clusters or associations (such as $\left[\mathrm{Y}_{\mathrm{Ce}}^{\prime}-\mathrm{V}_{\mathrm{O}}^{\mathrm{m}}{ }^{-1}{ }_{\mathrm{Ce}}\right]^{\times}$and $\left[\mathrm{Y}_{\mathrm{Ce}}^{\prime}-\mathrm{V}_{\mathrm{O}\lrcorner}^{\mathrm{m}}\right)$ accounts for the non-linear dependence. Thus, the strain-tension balance existing in high distortion of the octahedral is probably driven by oxygen defects, structure disordering and defect associations. No matter what the main contribution is, these different defect mechanisms interplay and dominate in different compositional ranges, giving rise to the abnormal lattice change at a constant oxygen deficiency.

(a)

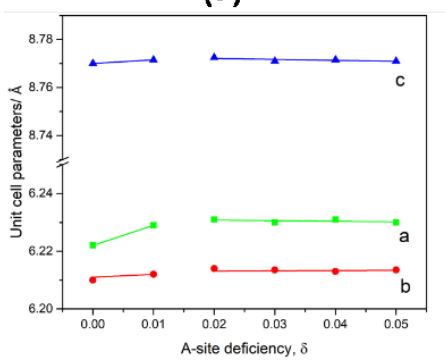

(b)

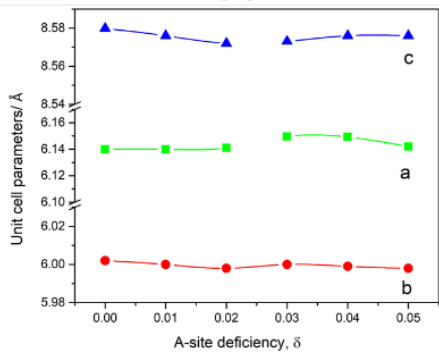

(c)

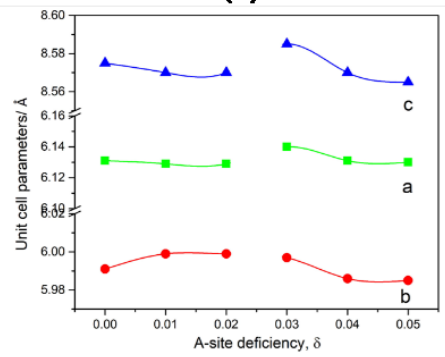

Fig.4. Unit cell parameters and volume dependence of A-site deficiency ( $\delta$ ): (a) $\mathrm{Ba}_{1-\delta} \mathrm{Ce}_{0.9} \mathrm{Y}_{0.1} \mathrm{O}_{2.95}$ $\delta$, (b) $\mathrm{Sr}_{1-\delta} \mathrm{Ce}_{0.9} \mathrm{Gd}_{0.1} \mathrm{O}_{2.95-\delta}$ and $\mathrm{Ba}_{1-\delta} \mathrm{Ce}_{0.9} \mathrm{Yb}_{0.1} \mathrm{O}_{2.95-\delta}[62]$.

\subsection{B-site substitution}

The substitution of divalent or trivalent cations at the B site can create more oxygen vacancies (acceptor doping) in lattices as a result of charge compensation (Eq.2), associated with structure distortion. Most of crystal structure retain pseudo-cubic symmetry or orthorhombic distortion with increasing concentration of dopants at the B site up to $20 \mathrm{~mol} \%$ [46, 66-69], despite some observations that acceptor doping exerts the formation of tetragonal or trigonal distortion [70], likely due to using lowerresolution neutron and X-ray powder diffraction data. That is, the effects of B-site doping on crystal phases and defect structures of proton-conducting perovskites are still in dispute.

Knight et al. [68, 71] investigated several doped strontium and barium cerate $\left(\mathrm{BaCe}_{0.9} \mathrm{Y}_{0.1} \mathrm{O}_{2.95}, \mathrm{BaCe}_{0.9} \mathrm{Gd}_{0.1} \mathrm{O}_{2.95}, \mathrm{BaCe}_{0.85} \mathrm{Pr}_{0.15} \mathrm{O}_{3}\right.$ and $\mathrm{SrCe}_{0.95} \mathrm{Y}_{0.05} \mathrm{O}_{2.975}$ ) with the refinement of high-resolution neutron powder diffraction. All of them were corresponding to orthorhombic space group Pmcn with $\mathrm{GdFeO}_{3}$ structure, and the cation substitution had slight effect on structure parameters, showing good matching 
between dopants and B-site cations (for example, the ionic radius of $\mathrm{Y}^{3+}, \mathrm{Gd}^{3+}$ andCe $\mathrm{Al}^{4+}$ in 6-fold coordination is $0.90,0.94$ and $0.87 \AA$, respectively). The main difference is that doped strontium cerate shows a great distortion by octahedral titling. Subsequently, Knight et al. [65] further verified the crystal structure was independent of doping levels in $\mathrm{BaCe}_{1-x} \mathrm{Nd}_{x} \mathrm{O}_{3-\delta}$ compositions $(0 \leq x \leq 0.2)$. However, Takeuchi et al. [69] reported that $\mathrm{BaCe}_{1-x} \mathrm{Y}_{x} \mathrm{O}_{3-\delta}$ compounds $(0 \leq x \leq 0.3)$ had orthorhombic Pmcn for $x \leq 0.1$ and rhombohedral $R \overline{3} c$ for $x \geq 0.15$. Kruth et al. [46] argued that over solid solution limit range, all compositions exhibited primitive orthorhombic and the phase transition was not observed, which is in accord with the results of Knight et al.. The contradictory results from Takeuchi et al. are primarily related to the nature of dopants, samples pretreatment and exposure to different atmospheres. Moreover, an axial metric of $a>b$ was further observed in refined unit cell parameters of $\mathrm{BaCe}_{0.9} \mathrm{Y}_{0.1} \mathrm{O}_{2.95}$ on basis of orthorhombic Pbnm setting conducted by Kruth et al. [42], as exhibited in Fig.9 $(x=0)$. This suggests that the $\mathrm{BO}_{6}$ octahedral is highly enlarged along the $a$-axis. The calculated orthorhombic strain (Eq.6), $\gamma$, is greatly negative, indicative of a highly distorted structure. This is because the regular octahedral along $b$-axis results in the metric of $\mathrm{b}>\mathrm{a}$ and shows a positive value. The calculated angles of $\mathrm{Ce} / \mathrm{Y}-\mathrm{O} 1-\mathrm{Ce} / \mathrm{Y}(c$-axis $)$ and $\mathrm{Ce} / \mathrm{Y}-\mathrm{O} 2-\mathrm{Ce} / \mathrm{Y}$ ( $a b$ plane) show a large deviation from $180^{\circ}$ and the octahedral rotates preferentially in the $[001]_{\mathrm{p}}$ direction than in the $[110]_{\mathrm{p}}$ plane.

Amsif [72] conducted a detailed study of the effects of rare-earth doping on structure parameters and proton mobility of $\mathrm{BaCe}_{0.9} \mathrm{Ln}_{0.1} \mathrm{O}_{3-\delta}(\mathrm{Ln}=\mathrm{La}, \mathrm{Nd}, \mathrm{Sm}, \mathrm{Gd}, \mathrm{Yb}$, $\mathrm{Tb}$ and $\mathrm{Y}$ ). The free volume, referring to the subtraction between the lattice unit cell volume and the ionic volume, shows an increasing linear dependence of the radius of dopant ions in Fig.5, whereas the tolerance factor decreases with the increasing ionic radius. Generally, more free volume can allow for more oxygen vacancies accommodation, while lower octahedral distortion favors oxygen ion and proton transport within perovskite structure. Such an opposite trend further demonstrates that the limited proton transport is a tradeoff between ion radii and its intrinsic chemical properties (such as electron structure and electronegativity). It can be seen that Gd and Sm doping near the intersection of two curves are reported to show highest total 
conductivity among the same doping level compared to other rare earth substitutions $[73,74]$. Further results of lattice parameters and distortions on $\mathrm{BaCe}_{0.9} \operatorname{Ln}_{0.1} \mathrm{O}_{3-\delta}(\mathrm{Ln}=$ $\mathrm{Nd}, \mathrm{Sm}, \mathrm{Gd}, \mathrm{Dy}, \mathrm{Yb}$ and $\mathrm{Y}$ ) compositions indicate that the lattice spaces along $b$ - and $c$-axis are constant irrespective of ion radii of dopants, while the values along a-axis increase with ion radii of dopants, responsible for the crystal deformation and oxygen vacancies contribution, leading to higher total conduction [75].

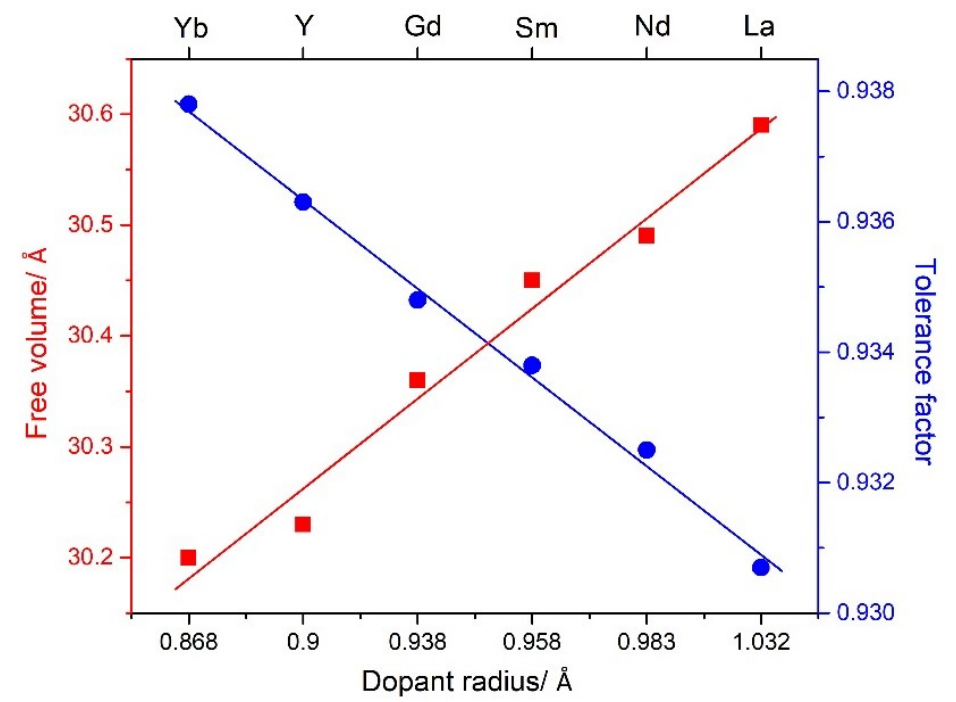

Fig.5. Dependence of free volume and tolerance factor on dopant ion radius in $\mathrm{BaCe}_{0.9} \mathrm{Ln}_{0.1} \mathrm{O}_{3-\delta}$ compositions [72].

There is evidence in analysis of Extended X-Ray Absorption Fine Structure (EXAFS) [76] that ionic size matching is not the necessary criterion for dopant accommodation at the $\mathrm{B}$ site. For instance, the ion radii of dopant $\operatorname{In}^{3+}(0.80 \AA), \mathrm{Y}^{3+}(0.90$ $\AA)$ and $\mathrm{Gd}^{3+}(0.938 \AA)$ are smaller, nearly equal and larger than that of $\mathrm{Ce}^{4+}(0.87 \AA)$, respectively. $\mathrm{Gd}^{3+}$ and $\mathrm{Y}^{3+}$ dopants are found to have limited solubility in $\mathrm{BaCeO}_{3}$, triggering local perturbation in host matrix to produce high disorder structure. While dopant $\mathrm{In}^{3+}$ with the complete solubility arranges the reorganization of the host lattice in a highly symmetrical coordination around local dopant site.

In case of doped $\mathrm{BaZrO}_{3}$, the site selectivity of $\mathrm{Sc}, \mathrm{Y}, \mathrm{Sm}, \mathrm{Eu}$, and Dy dopants into A site and B site was investigated by Han et al.[77-79]. Given that the ionic radii of cations in 6-fold coordination of $\mathrm{Y}^{3+}(0.900 \AA), \mathrm{Dy}^{3+}(0.912 \AA), \mathrm{Eu}^{3+}(0.947 \AA)$ and $\mathrm{Sm}^{3+}(0.958 \AA)$ are much larger than that of the $\mathrm{Zr}^{4+}$ cation $(0.72 \AA)$, and ionic radii in 12-fold coordination $\left(\mathrm{Y}^{3+}(1.251 \AA), \mathrm{Dy}^{3+}(1.255 \AA)\right.$ and $\left.\mathrm{Eu}^{3+}(1.295 \AA)\right)$ are by close 
orders of magnitude smaller than that of $\mathrm{Ba}^{2+}$ cation (1.61 $\AA$ ), Y, Sm and Eu dopants appear to mainly occupy B-site and show a partial A-site occupation, as well as the expansion of lattice volume with the increasing dopant concentration (Fig.6). While for doping of Sc, since the radius of the $\mathrm{Sc}^{3+}$ cation $(0.745 \AA)$ is close to that of the $\mathrm{Zr}^{4+}$ cation, the occupancy entirely lie in the B site and the lattice volume shows no obvious change.

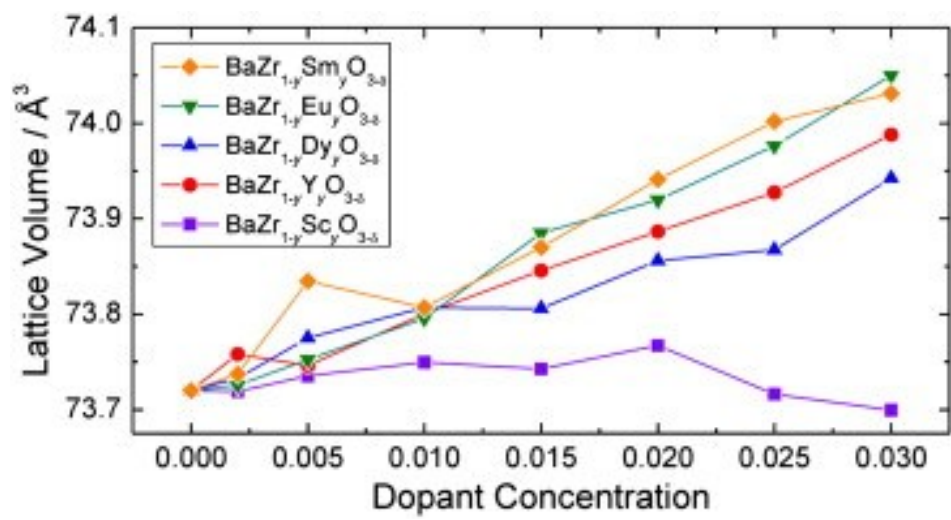

Fig.6. The lattice volumes of the samples of $\mathrm{BaZr}_{1-y} \mathrm{M}_{y} \mathrm{O}_{3-\delta}(\mathrm{M}=\mathrm{Sc}, \mathrm{Y}, \mathrm{Sm}, \mathrm{Eu}, \mathrm{Dy} ; 0 \leqslant x \leqslant$

0.2) sintered at $1600{ }^{\circ} \mathrm{C}$ for $24 \mathrm{~h}[77]$.

It should be concerned that, generally, the maximum value of these dopants to achieve the highest conductivity is up to $15-25 \mathrm{~mol} \%$ depending on the nature of dopants. For example, a typical composition of $\mathrm{BaZr}_{0.8} \mathrm{Y}_{0.2} \mathrm{O}_{3-\delta}$ with the highest hydration contains 0.2 protons per unit cell, indicating only $6.7 \%$ of the oxygen atoms as proton defects. The other oxygen atoms contribution is ascribed to M-O-M bridges ( $\mathrm{M}=\mathrm{Zr}$ or $\mathrm{Y})$ [80]. This implies that only low effective proportion of oxygen vacancies can facilitate proton migration. Kilner et al. [81] and Mather et al. [82] suggested that the presence of maximum concentration was related to the formation of associated defect pairs between a neighboring dopant ions and oxygen vacancies or neutral trimer clusters. Typical dopant-vacancy association reactions of Y-doped barium zirconate are expressed as follows:

$$
\begin{aligned}
& \mathrm{Y}_{\mathrm{Zr}}^{\prime}+\mathrm{V}_{\mathrm{O}}^{\bullet \bullet} \rightarrow\left[\mathrm{Y}_{\mathrm{Zr}}^{\prime}-\mathrm{V}_{\mathrm{O}}^{\bullet \bullet}\right]^{\bullet} \quad \text { defect pairs } \\
& \mathrm{Y}_{\mathrm{Zr}}^{\prime}+\mathrm{V}_{\mathrm{O}}^{\bullet \bullet}+\mathrm{Y}_{\mathrm{Zr}}^{\prime} \rightarrow\left[\mathrm{Y}_{\mathrm{Zr}}^{\prime}-\mathrm{V}_{\mathrm{O}}^{\bullet \bullet}-\mathrm{Y}_{\mathrm{Zr}}^{\prime}\right]^{\times} \text {neutral trimer clusters }
\end{aligned}
$$

The trapped oxygen vacancies in the dopant-vacancy associations are difficult to 
participate in proton transport, which in turn lower the concentration of free oxygen vacancies, which is analogous to the concept of free volume. The evidence of the minimum activation energy is correlated with the maximum proton conductivity as the dopant content increases, which is inspired from the ceria solid solution investigated by Faber et al. [83]. With higher dopant levels, more associated defects tend to give rise to an ascending activation energy (Fig.7). Recently, Yamazaki et al. [80] also noted that protons had to overcome both proton-dopant associated energy $\left(29 \mathrm{~kJ} \mathrm{~mol}^{-1}\right)$ and activation energy $\left(16 \mathrm{~kJ} \mathrm{~mol}^{-1}\right)$ to achieve long-range transport motion. An extended range of $0.2 \leqslant x \leqslant 0.6$ in $\mathrm{BaZr}_{1-\mathrm{x}} \mathrm{Y}_{\mathrm{x}} \mathrm{O}_{3-\delta}$ composition investigation [84] indicates larger proton uptake but lower conductivity with increasing yttrium content. This means that the proton conductivity is not equal to proton uptake, in good agreement with proposed defect association mechanisms. This insight provides a motivation to seek suitable alternative dopants with reduced association energies to obtain higher conductivity.

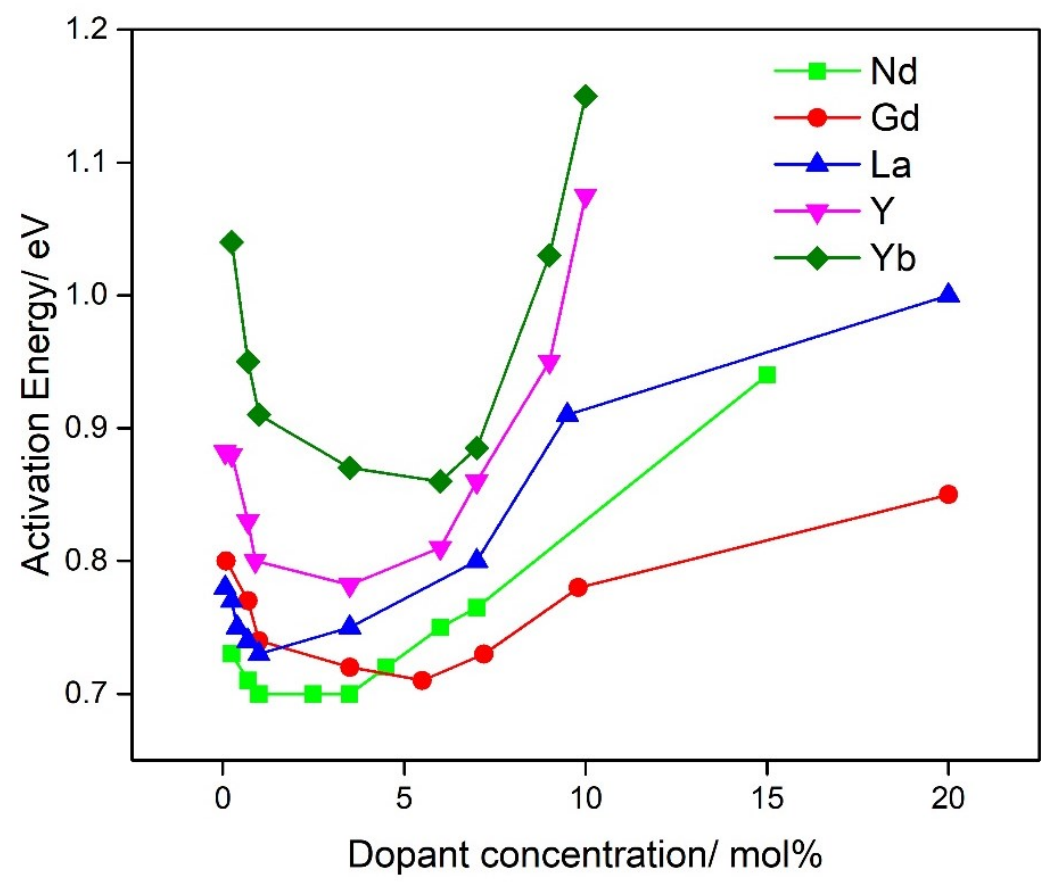

Fig.7. Activation energy as a function of dopant concentration in ceria solid solution [83].

\subsection{Cross substitution}

Cation cross-substitution may occur in A-site defects stemming from A-site 
deficiency or cations evaporation, in which the acceptor dopant at the B site is acceptable to partially incorporate into A site. Such undesirable accommodation mechanisms seem to be plausible at the expense of oxygen vacancies to stabilize the perovskite phase. In case of $\mathrm{Ba}_{x} \mathrm{Ce}_{1-y} \mathrm{Y}_{y} \mathrm{O}_{3-\delta}$, the defect reaction is expressed in Eq. 15 or Eq. 16.

$$
\begin{gathered}
2 \mathrm{Ba}_{\mathrm{Ba}}^{\times}+\mathrm{Y}_{2} \mathrm{O}_{3}+\mathrm{V}_{\mathrm{O}}^{\bullet \bullet} \rightarrow 2 \mathrm{Y}_{\mathrm{Ba}}^{\bullet}+\mathrm{O}_{\mathrm{O}}^{\times}+2 \mathrm{BaO} \uparrow \\
2 \mathrm{CeO}_{2}+\mathrm{Y}_{\mathrm{Ce}}^{\prime}+\mathrm{V}_{\mathrm{O}}^{\bullet \bullet} \rightarrow \mathrm{Y}_{\mathrm{Ba}}^{\bullet}+2 \mathrm{Ce}_{\mathrm{Ce}}+4 \mathrm{O}_{\mathrm{O}}^{\times}
\end{gathered}
$$

The dopant partitioning over A and B sites is strongly dependent on the nature of dopant ions, as well as its ion radii. For example, the size of 12 -coordinated $\mathrm{Y}^{3+}(1.25 \AA)$ is ca.. $29 \%$ smaller than that of 12 -coordinated $\mathrm{Ba}^{2+}(1.61 \AA)$ and by $c a .30 \%$ larger than $\mathrm{Ce}^{4+}(0.87 \AA)$ in 6-fold coordination. Thus, size mismatching of $\mathrm{Y}^{3+}$ at the $\mathrm{A}$ and $\mathrm{B}$ site is comparable, making cation cross-substitution possible. Recent atomistic studies [85, 86] revealed that the solution energy of dopant partitioning into A site was about 2-3 times larger than that of the dopant occupying the B site. The calculated solution energies mean that rare earth cations are mainly accommodated at the B site and prefer to partition into the A site with increasing the ionic size. Among them, $\mathrm{Nd}$ is considered to be a promising partitioning dopant with the lowest positive reaction energy (Fig.8). Note that trivalent dopants should accommodate preferentially at the B site due to the large-size requirement for the B site. Some other experimental and computational results suggest that alkali metals $(\mathrm{K}, \mathrm{Na}, \mathrm{Rb}, \mathrm{Cs})$ may be as efficient A-site acceptor dopants in $\mathrm{BaZrO}_{3}$ to reduce complex formation between the acceptors and the mobile protons and thus impede partitioning in perovskite oxides [87-89]. 


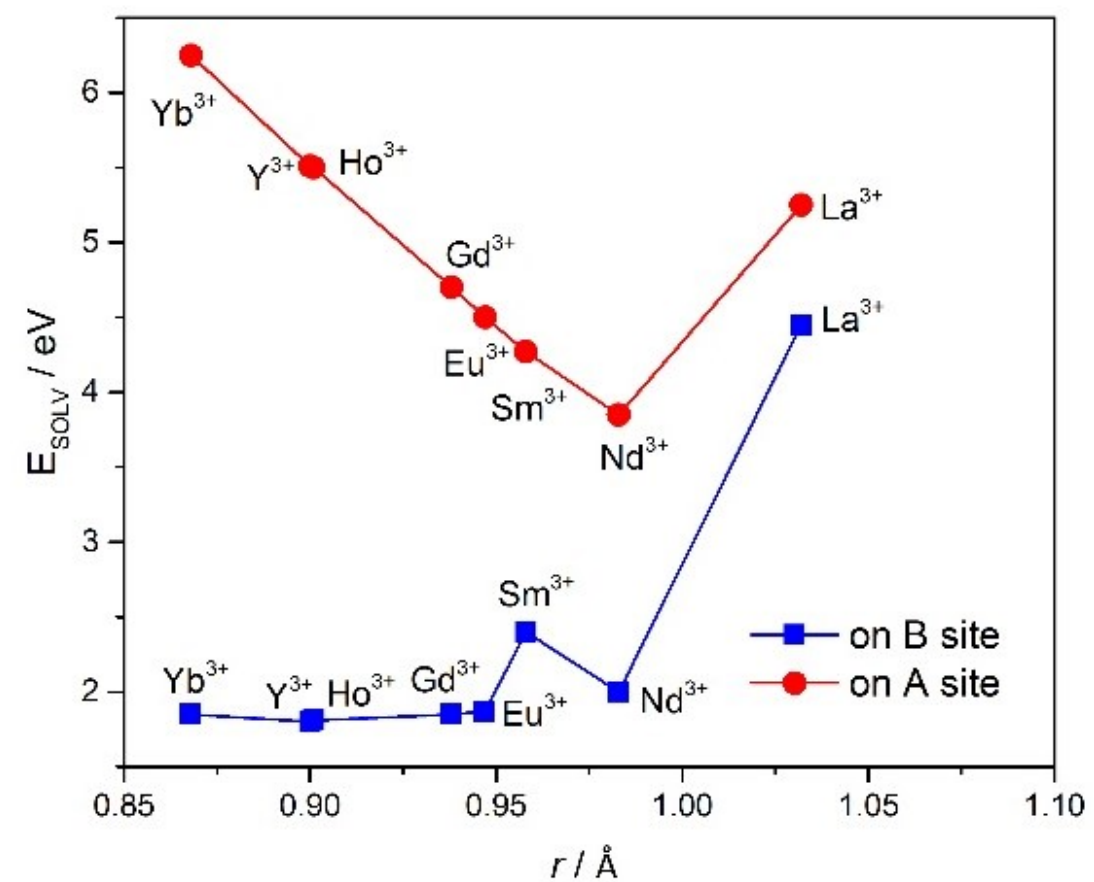

Fig.8. Solution energies of different ion sizes for trivalent dopants on $\mathrm{Ba}$ and $\mathrm{Ce}$ site in orthorhombic $\mathrm{BaCeO}_{3}[85]$.

The strategy of co-doping with $\mathrm{La}^{3+}$ at the $\mathrm{A}$ site and $\mathrm{Y}^{3+}$ at the $\mathrm{B}$ site, giving the formula of $\mathrm{Ba}_{1-x} \mathrm{La}_{x} \mathrm{Ce}_{0.9-x} \mathrm{Y}_{0.1+x} \mathrm{O}_{2.95}(0 \leq x \leq 0.15)$ compositions, is taken to suppress $\mathrm{Y}^{3+}$ dopant cross-substitution into A site and thereby retain a maximum oxygen vacancy concentration in the lattice [42]. The results of refined unit parameters plotted in Fig.9(a) indicates that the stretch of $\mathrm{CeO}_{6}$ octahedral reduces along the a-axis with doping $x$. In Fig.9(b), the Ce/Y-O2-Ce/Y bond angles decrease to minimum at 0.05 and then increases with further doping. This implies that for $0 \leq x \leq 0.05$, octahedral titling increases in $[110]_{\mathrm{p}}(a b$ plane) and reduces after binary join of 0.05 . While octahedral rotation decreases monotonically along $[001]_{\mathrm{p}}$ (c-axis) with doping, as evidenced by reduced $\mathrm{Ce} / \mathrm{Y}-\mathrm{O} 1-\mathrm{Ce} / \mathrm{Y}$ bond angles. The orthorhombic strain, $\mathcal{\varepsilon}$, is found to increase with increasing $x$ in Fig.9(c), which means that a reversed axis is observed from $a>b$ to $b>a$. Furthermore, the octahedral basal plane ( $a b$ plane) elongation, $\gamma$, is significant in the compositional range of $0 \leq x \leq 0.05$ in Fig.9(d). Such these evidences indicate that the octahedral elongation along $c$-axis and distortion of octahedral plane are competing in co-doping compositions. For $0 \leq x \leq 0.05$, the deformation of $a b$ plane is more significant. If high doping levels are increased $(x>0.05)$, the octahedral titling along $c$-axis is dominated. These structural variations suggest that two competing 
distortion mechanisms occur over the compositional range, which has significant influence on the oxygen vacancy concentration, as well as the protonic defect concentration.
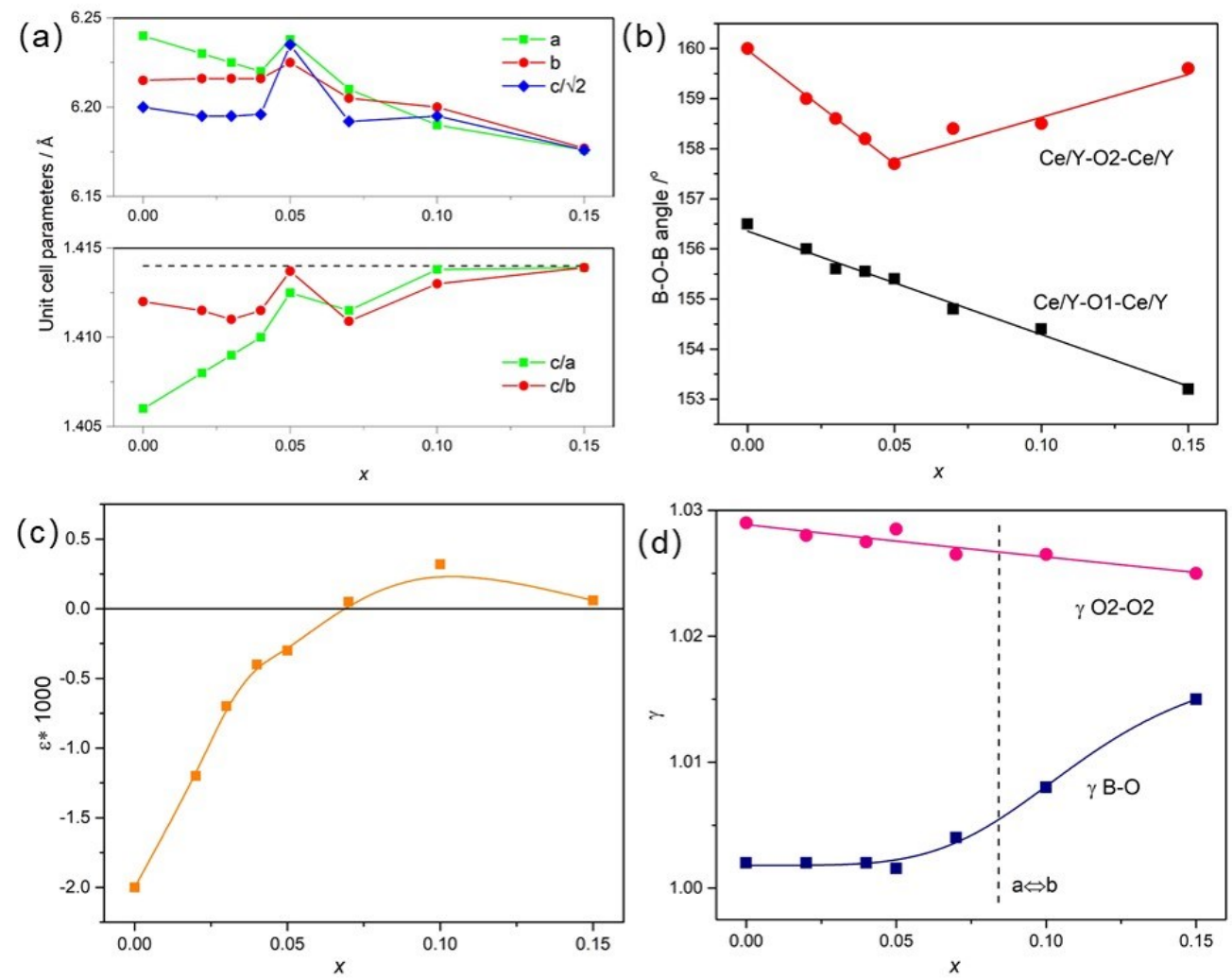

Fig.9. Structure parameters of $\mathrm{Ba}_{1-x} \mathrm{La}_{x} \mathrm{Ce}_{0.9-x} \mathrm{Y}_{0.1+x} \mathrm{O}_{2.95}$ with dependence of composition $x$. (a) unit cell parameters, (b) variations of bond angles, (c) Orthorhombic strain, (d) Octahedral deformation [42].

\section{Defect Chemistry in relation to its properties}

The tailoring of cation non-stoichiometry, oxygen vacancies, proton defects, as well as electronic holes in oxides are primary strategies to manipulate functional properties (such as proton transport, chemical stability and electrochemical catalysis) for proton-conducting applications. A fundamental understanding of compositionstructure-property relationship is still incomplete, making it difficult to tune existing materials.

\subsection{Transport properties}

\subsubsection{Non-stoichiometry at $A$ and $B$ sites}


Numerous efforts have been devoted to exploring transport behaviors of $\mathrm{SrCeO}_{3}$, $\mathrm{BaCeO}_{3}$ and $\mathrm{BaZrO}_{3}$ based perovskites, particularly in acceptor-doped compositions. The strong effects of A-site-cation deficiency and excess indicate that undoped $\mathrm{BaCeO}_{3}$ and $\mathrm{BaZrO}_{3}$ compositions with small $\mathrm{Ba}$ deficiencies show slight or similar conductivity as stoichiometric ones, whereas the conductivity is significantly increased in Ba-excess compositions, with their Ba-grain boundary enrichment, as dictated in section 3.1. However, varying trends in conduction properties are observed in different acceptor-doped compositions. The proton conductivity of Gd-doped barium cerate, $\mathrm{Ba}_{x} \mathrm{Ce}_{0.85} \mathrm{Gd}_{0.15} \mathrm{O}_{3-\delta}(0.96 \leq x \leq 1.04)$, was reported to increase with increasing $\mathrm{Ba}$ content in $\mathrm{H}_{2} \mathrm{O}$-saturated argon atmospheres at $500{ }^{\circ} \mathrm{C}$, in which the presence of $\mathrm{CeO}_{2}$ precipitates in $4 \mathrm{~mol} \%$ Ba-deficient composition significantly lowered the conductivity by a half order of magnitude compared to stoichiometric compositions [52]. Whereas the composition of $5 \mathrm{~mol} \% \mathrm{Ba}$ deficiency in Y-doped barium cerate $\left(\mathrm{Ba}_{x} \mathrm{Ce}_{0.9} \mathrm{Y}_{0.1} \mathrm{O}_{3-\delta}\right.$, $0.80 \leq x \leq 1.20$ ) showed the highest conductivity in the temperature range of $600-800^{\circ} \mathrm{C}$, regardless of atmosphere dependence [90]. Proton and total conductivity of $\mathrm{Ba}_{x} \mathrm{Ce}_{0.97} \mathrm{Nd}_{0.03} \mathrm{O}_{3}-\delta(0.90 \leq x \leq 1.10)$ in humid air from $700-900{ }^{\circ} \mathrm{C}$ measured by Sharova et al. [91], however, were found to increase with increasing Ba content $(x \leq 1.0)$, but weakly dependent on $\mathrm{Ba}$ excess $(x>1.0)$. There are several explanations that account for the compositional dependence of conductivity: (i) Both A-site-deficient levels and B-site doping levels affect oxygen vacancies and proton defects to some extent; (ii) The concentration of protons, oxygen ions or electron holes charge carriers is greatly related to the exposed atmosphere and operating temperature; (iii) Defect clustering and/or association with dopant ions is expected to occur at low temperatures.

In contrast to Ba deficiency, the proton conductivity of Sr-deficient stoichiometry $\left(\mathrm{Sr}_{1-x} \mathrm{Ce}_{0.9} \mathrm{Yb}_{0.1} \mathrm{O}_{3-\delta}, 0 \leq x \leq 0.06\right)[63]$ is likely to increase with increasing $x$ in the range of lower deficient levels $(x \leq 0.04)$ probably due to the formation of additional oxygen vacancies via Eq.17.

$$
\mathrm{Sr}_{\mathrm{Sr}}^{\times}+\mathrm{O}_{\mathrm{O}}^{\times} \rightarrow \mathrm{V}_{\mathrm{Sr}}^{\prime \prime}+\mathrm{V}_{\mathrm{O}}^{\bullet \bullet}+\mathrm{SrO}
$$

But for high levels of Sr defects, partial cross-substitution of Yb dopant over A and B 
sites consumes oxygen vacancies, responsible for the decreased conductivity. This change of defects is associated with the maximum volume to relieve octahedral strain.

With regard to nominally stoichiometric $\mathrm{Ba}$ content, nearly all of rare earth elements (e.g., Gd, Pr, Nd, Y, Yb, Dy, In, Sm, Ho, Er) have been incorporated into the B site to tune defect chemistry and thus control the proton transport properties in great detail [72, 92-96], in addition to some transition metals like $\mathrm{Ni}, \mathrm{Cu}, \mathrm{Co}, \mathrm{Zn}$ as sintering aids. Among them, Gd-doped $\mathrm{BaCeO}_{3}$ shows the highest conductivity regardless of atmospheres and temperatures in agreement with the evidence of the tradeoff between free volume and tolerance factor in Fig. 5 [72], which exerts a critical ionic radius for ion transport. In contrast, $20 \% \mathrm{Y}$-doped $\mathrm{BaZrO}_{3}$ shows a total conductivity of over 0.01 $\mathrm{S} \mathrm{cm}^{-1}$ achieved even at $500{ }^{\circ} \mathrm{C}$, outperforming other doped zirconate [70, 97]. In $\mathrm{BaCeO}_{3}-\mathrm{BaZrO}_{3}$ mixed system, Y-containing samples generally have higher proton conductivity than Gd-doped ones. Obviously, $\mathrm{Gd}$ is a poor dopant for $\mathrm{BaZrO}_{3}$, but an excellent dopant for $\mathrm{BaCeO}_{3}$. From the lattice basicity point of view, with increasing the basicity of the B-site cation (i.e., reducing the electronegativity of the B-site cation), the proton transport behavior is more significant. The truth is Y dopant almost doesn't change the lattice oxygen basicity, whereas other reported dopants, in fact, tend to reduce the proton mobility with entropic destabilization of protonic defects [1]. In addition, the proton transport is not only related to the symmetry of the perovskite, but also to the local structure and percolation induced by the acceptor dopant at the B site [98]. For example, though the ionic radii of $\mathrm{In}^{3+}$ and $\mathrm{Sc}^{3+}$ relatively fit to that of $\mathrm{Zr}^{4+}$, In- and doped $\mathrm{BaZrO}_{3}$ show much lower proton conductivity compared to Y-doped $\mathrm{BaZrO}_{3}[99]$. On the other hand, the electrical conductivity of Y-doped barium cerate is generally higher than Y-doped barium zironate in same doping level, whereas the bulk conductivity is in opposite trend. This is because the conductivity measurement is usually performed above $600{ }^{\circ} \mathrm{C}$, where the grain boundary contribution is unavailable from impedance spectra (the similar case in Fig.10 (f)). Typically, the bulk and grain boundary contribution show capacitance values of $\mathrm{pF} \mathrm{cm}^{-1}$ and $\mathrm{nF} \mathrm{cm}^{-1}$, respectively. Only when the temperature below $250{ }^{\circ} \mathrm{C}$, the grain boundary and grain interior processes can be separated completely by fitting the data with equivalent 
circuits, as showed in Fig.10(a)-(e). It can be seen that Gd-doped compositions show the lowest bulk and grain boundary resistance, resulting in the highest conductivity of the series of doped $\mathrm{BaCeO}_{3}$ samples. Due to the refractory nature of $\mathrm{BaZrO}_{3}$, poor densification and small grain size give rise to a dramatic increase in grain boundary resistance relative to $\mathrm{BaCeO}_{3}$. To overcome this issue, a small amount of $\mathrm{ZnO}$ [100], $\mathrm{NiO}$ [101], $\mathrm{CoO}$ [102] and $\mathrm{CuO}$ [103] dopants are incorporated to the $\mathrm{B}$ site to reduce the grain boundary resistance and thereby improve the proton mobility. Recently, NiOassisted solid-state reaction has been intensively adopted to enhance the sinterability of BCZY electrolyte. As a result, the formation of Ni-doped BCZY composition readily enables in situ exsolution of Ni nanoparticles anchoring on the BCZY surface under reducing conditions, which is responsible for the enhancement of conductivity and durability $[104,105]$.
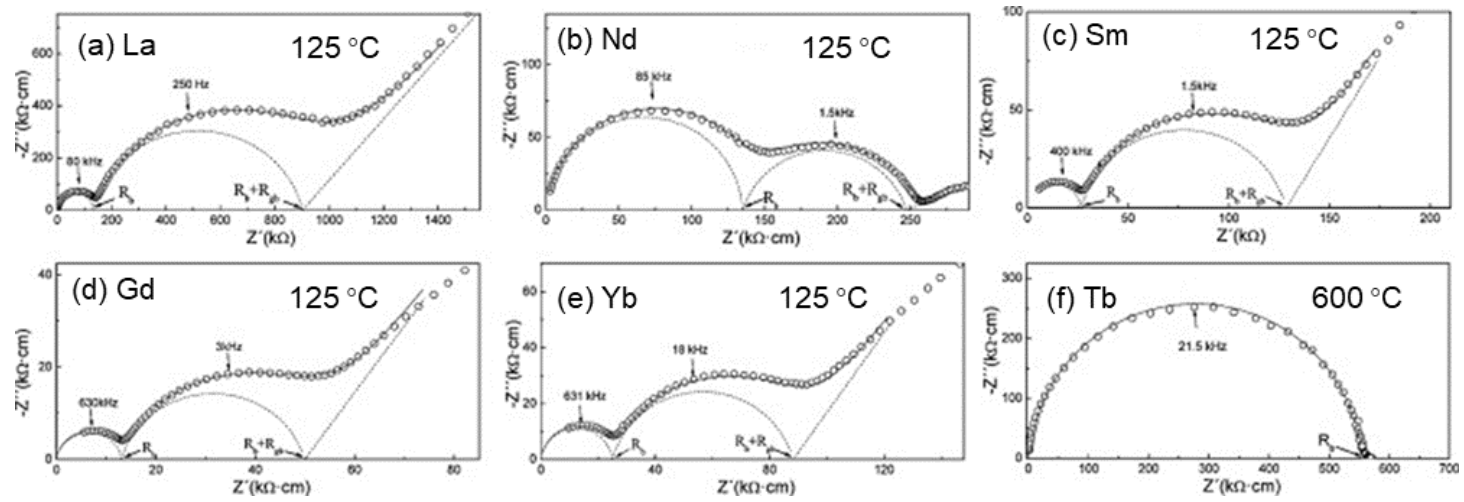

Fig.10. Impedance spectra for $\mathrm{BaCe}_{0.9} \mathrm{Ln}_{0.1} \mathrm{O}_{3-\delta}$ pellets sintered at $1400{ }^{\circ} \mathrm{C}$ for $4 \mathrm{~h}$ : $\mathrm{Ln}=($ a) $\mathrm{La}$, (b) $\mathrm{Nd}$, (c) Sm, (d) $\mathrm{Gd}$ and (e) $\mathrm{Yb}$ measured at $125^{\circ} \mathrm{C}$ and (f) $\mathrm{Tb}$ in wet $5 \% \mathrm{H}_{2}-\mathrm{Ar}$ and at $600{ }^{\circ} \mathrm{C}$ [72].

Furthermore, Han et al. [78] thoroughly investigated the correlation between structure and transport properties on a series of rare earth element doped $\mathrm{BaZr}_{0.8} \mathrm{M}_{0.2} \mathrm{O}_{3-}$ ${ }_{\delta}(\mathrm{M}=\mathrm{Sc}, \mathrm{Y}, \mathrm{In}, \mathrm{Pr}, \mathrm{Nd}, \mathrm{Sm}, \mathrm{Eu}, \mathrm{Gd}, \mathrm{Tb}, \mathrm{Dy}, \mathrm{Ho}, \mathrm{Er}, \mathrm{Tm}, \mathrm{Yb}$ and In). The summarized bulk conductivities in Fig.11(a) show that the apparent high bulk conductivities of doped zirconates are primarily relied on the ion radii of dopants, excluding grain boundary contribution. The dopants with the ion radii ranging from 0.87 to 0.91 ( $\mathrm{Yb}$, $\mathrm{Tm}, \mathrm{Er}, \mathrm{Y}$ and Ho ) tend to incorporate into parent perovskites and significantly increase proton conductivity, associated with a large lattice expansion upon hydration. In most cases, the samples with high proton concentrations have high proton conductivity. Only 
Sc-doped behaves a low proton conductivity, as well as a small lattice expansion, most likely due to proton trapping in the local structure [106]. This indicates that the apparent proton conductivity and the lattice expansion via hydration are well correlated. In addition, an interesting relationship was observed between various $\mathrm{Y}$ concentration and the corresponding conductivity, as showed in Fig.11(b) [107]. The low grain boundary contribution primarily accounts for the low proton conduction, especially when Y content is from 0.02 to 0.15 . Unfortunately, the intrinsic correlation of dopants and grain boundary conductivity is not fully demonstrated in terms of defect chemistry. To better understand the influence of different non-stoichiometric mechanisms on proton conductivity, further analysis of relationships between various defects formation, octahedral distortion and conduction, associated with high-resolution neutron, X-ray and electron diffraction and simulation studies, are required.

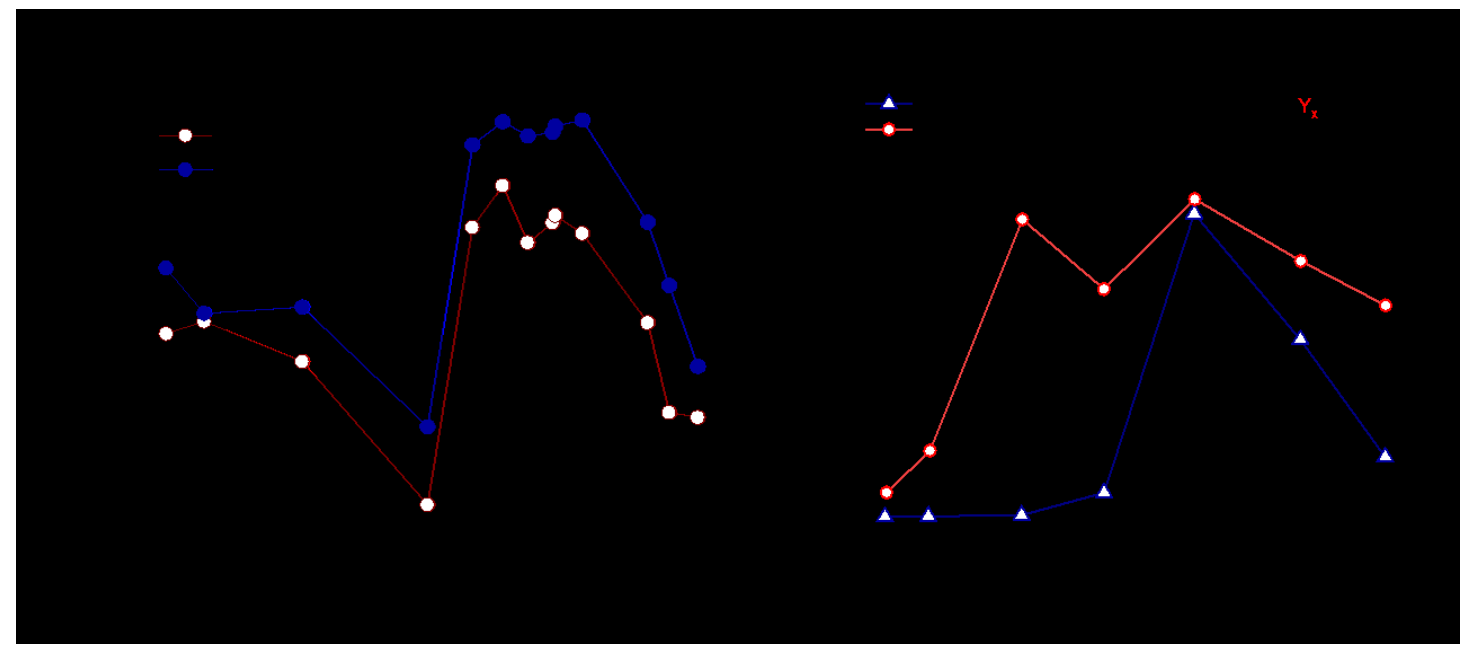

Fig.11. Bulk conductivity of $\mathrm{BaZr}_{0.8} \mathrm{M}_{0.2} \mathrm{O}_{3-\delta}$ in wet and dry $\mathrm{H}_{2}$ atmospheres [78]. Bulk conductivity and effective grain-boundary conductivity of $\mathrm{BaZrO}_{3}$ doped with various $\mathrm{Y}$ content at $300^{\circ} \mathrm{C}$ in wet $\mathrm{H}_{2}\left(P\left(H_{2} \mathrm{O}\right)=0.05 \mathrm{~atm}\right)[107]$.

\subsection{2 $\mathrm{P}\left(\mathrm{H}_{2} \mathrm{O}\right), \mathrm{P}\left(\mathrm{O}_{2}\right)$ and temperature dependences}

The transport properties of proton conductors are found to be as functions of temperature, vapor partial pressure $\left(P_{H_{2} O}\right)$, and oxygen partial pressure $\left(P_{O_{2}}\right)$. For high temperature and high $P_{O_{2}}$, the composition exhibits both ionic and p-type electronic conductivity; When at low $P_{O_{2}}$ and high temperatures or under wet oxidizing atmospheres and low temperatures, it shows a mixed ionic (proton and oxygen ion) conductor; If at low $P_{O_{2}}$ and low temperatures, it turns to a pure protonic conductor. 
While under dry oxidizing atmospheres and low temperatures, it may be a pure oxygen ionic conductor. These peculiarities in different conditions are determined by the defect chemical equilibriums of oxygen vacancies $\left(\mathrm{V}_{\mathrm{O}}^{\bullet \bullet}\right)$, doping defects $\left(\mathrm{M}_{\mathrm{Ce}}^{\prime}\right)$, protons $\left(\mathrm{OH}_{\mathrm{O}}^{\bullet}\right)$, electron holes $\left(\mathrm{h}^{\bullet}\right)$ and electrons $\left(\mathrm{e}^{\prime}\right)$ in perovskite oxides.

Most acceptor doped proton-conducting oxides (whether in dry or wet atmospheres) have a general tendency (Fig.12(a)): the observed $\sigma$ decreases with $P_{\mathrm{O}_{2}}^{-1 / 4}$ dependence (n-type conduction) at very low oxygen partial pressures, in which oxygen vacancies and electrons are created according to Eq.18.

$$
\begin{aligned}
& \mathrm{O}_{\mathrm{O}}^{\times} \rightarrow 1 / 2 \mathrm{O}_{2}+\mathrm{V}_{\mathrm{O}}^{\bullet \bullet}+2 \mathrm{e}^{\prime} \\
& 1 / 2 \mathrm{O}_{2}+\mathrm{V}_{\mathrm{O}}^{\bullet \bullet} \rightarrow \mathrm{O}_{\mathrm{O}}^{\times}+2 \mathrm{~h}^{\bullet}
\end{aligned}
$$

Whereas for some perovskite oxides, the $\sigma$ keeps constant at low oxygen partial pressures. In contrast, the total conductivity is increased with $P_{\mathrm{O}_{2}}^{1 / 4}$ dependence at high oxygen partial pressures (p-type conduction )[108, 109], where electron holes can be introduced via Eq.19. To be more precise, Fig.12(b) shows simulated plots of main defects on a $5 \mathrm{~mol} \%$ Y-doped strontium cerate at $700{ }^{\circ} \mathrm{C}$ conducted by Song et al. [110]. It can be seen that the concentrations of oxygen vacancies, doping defects and protons are nearly constant with dependence of oxygen partial pressure, except for an increase at extremely low $\mathrm{P}_{2}$. The concentration curves of holes and electrons are symmetrical around n-p transition region, in which a offset is established due to some defect equilibriums happen, e.g., $\left[\mathrm{Y}^{\prime}{ }_{\mathrm{Ce}}\right]=2\left[\mathrm{~V}_{\mathrm{O}}^{\bullet \bullet}\right]$ at low water vapor pressure and $\left[\mathrm{Y}^{\prime}{ }_{\mathrm{Ce}}\right]=$ $2\left[\mathrm{OH}_{\mathrm{O}}^{\bullet}\right]$ at high water vapor pressure, leading to a plateau region in Fig.12(b). These model results are in good agreement with experimental investigations that the concentration of oxygen vacancies in $\mathrm{BaCe}_{0 .} \mathrm{Ln}_{0.1} \mathrm{O}_{3-\delta}(\mathrm{Ln}=\mathrm{Sm}, \mathrm{Tb}, \mathrm{Yb}$ and $\mathrm{Y})$ are $P_{o_{2}}$ independent within a certain oxygen partial pressure range [111]. However, the conductivity of $\mathrm{BaCe}_{0.9} \mathrm{Nd}_{0.1} \mathrm{O}_{3-\delta}$ was found to increase with increasing $P_{o_{2}}$ above $700^{\circ} \mathrm{C}$, whereas the trend was reverse under $700{ }^{\circ} \mathrm{C}[112]$. This can be explained by the changes of oxygen vacancies derived from the oxidation of $\mathrm{Nd}$ ions from trivalent to tetravalent as an increase in $P_{o_{2}}$. 

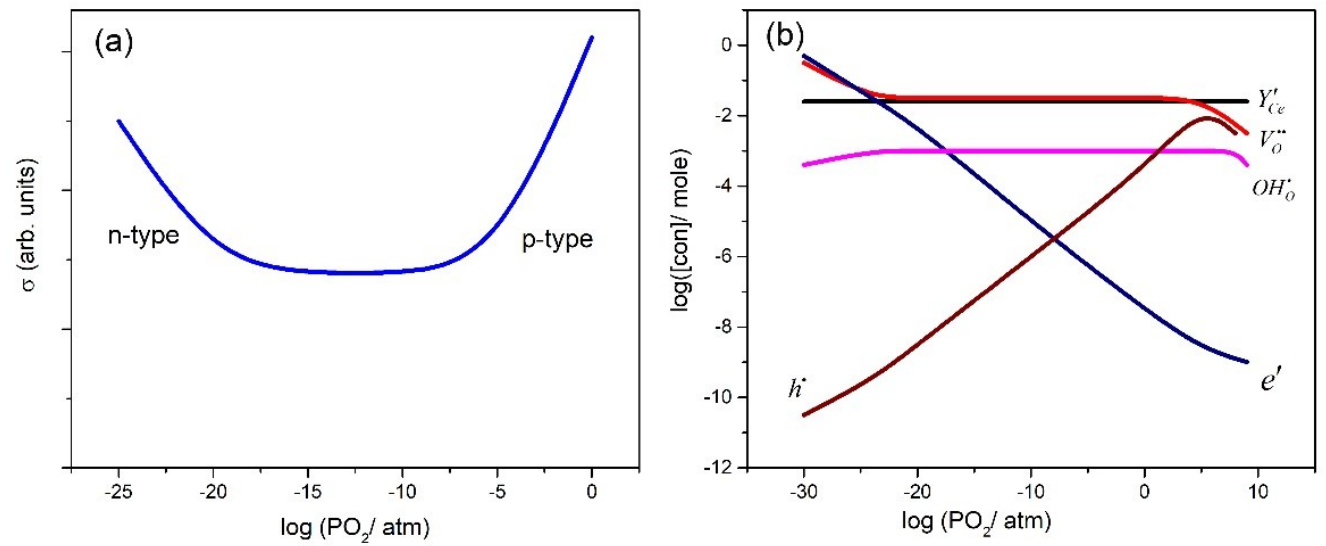

Fig.12. (a)The electrical conductivity of $\mathrm{SrCe}_{0.9} \mathrm{Y}_{0.1} \mathrm{O}_{3-\delta}[109]$ and (b) main defect concentrations in $\mathrm{SrCe}_{0.95} \mathrm{Y}_{0.05} \mathrm{O}_{3-\delta}$ as a function of $\mathrm{P}\left(\mathrm{O}_{2}\right)$ at fixed $P\left(\mathrm{H}_{2} \mathrm{O}\right)=10^{-2}$ atm and $700{ }^{\circ} \mathrm{C}$ [110].

Fig.13(a) shows $\mathrm{P}\left(\mathrm{H}_{2} \mathrm{O}\right)$ dependence of calculated $\sigma$ of different defects on $\mathrm{BaCe}_{0.9} \mathrm{Y}_{0.1} \mathrm{O}_{3-\delta}$ oxides [111]. It can be seen that the conductivity of proton defects increases, while the values of electron holes and oxygen vacancies slightly decrease with increasing vapor partial pressure, corresponding to the concentration results of different defects showed in Fig.13(b). Interestingly, The value of total $\sigma$ shows a weak dependence on $\mathrm{P}\left(\mathrm{H}_{2} \mathrm{O}\right)$. This is due to oxygen vacancies and proton domination in this condition. Oishi et al. [111] also reported the temperature dependence on experimental conductivities, as depicted in Fig.13(c) and (d). As expected, the $\sigma\left(\mathrm{O}^{2-}\right)$ and $\sigma_{\mathrm{h}}$ are increased with increasing temperature, while the $\sigma\left(\mathrm{OH}_{\mathrm{O}}^{\bullet}\right)$ increases with increasing temperature below $700{ }^{\circ} \mathrm{C}$ and decreases above $700{ }^{\circ} \mathrm{C}$. It is reasonable to conclude that proton conduction is predominant at low temperatures, and upon heating, protons are gradually dehydrated from the lattice, accompanying with large numbers of free oxygen vacancies available for mobility. During dehydration process the mixed oxide-ion and p-type conduction becomes dominant, instead of proton conduction. A comparison of slight $\mathrm{P}\left(\mathrm{O}_{2}\right)$ variation between Fig.13(c) and (d) suggests that proton conductivity is weakly dependent of oxygen partial pressure $\left(\mathrm{P}\left(\mathrm{O}_{2}\right)\right.$ range from 1 to $10^{-4}$ bar $)$ and that p-type conduction is higher in more oxidizing conditions. 

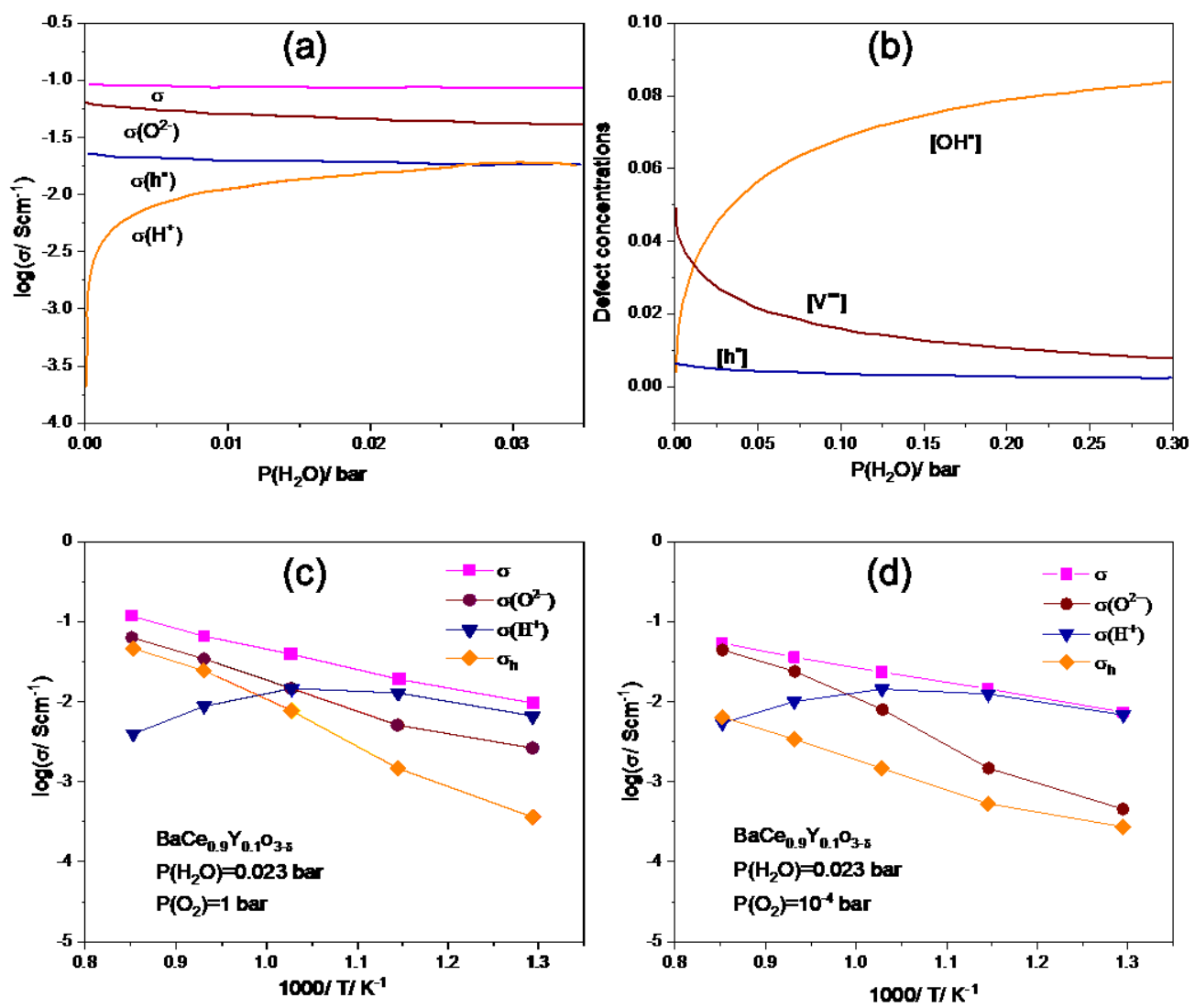

Fig.13. Plots of $\mathrm{P}\left(\mathrm{H}_{2} \mathrm{O}\right)$ dependence of (a) the calculated conductivities and (b) the concentrations of defects at $\mathrm{P}\left(\mathrm{O}_{2}\right)=10^{-2} \mathrm{bar}$ and $800^{\circ} \mathrm{C}$. The values of conductivities as a function of the reciprocal temperature at (c) $\mathrm{P}\left(\mathrm{O}_{2}\right)=1$ bar and (d) $\mathrm{P}\left(\mathrm{O}_{2}\right)=10^{-4}$ bar [111].

\subsection{Chemical stability and hydration behavior}

Even though $\mathrm{BaCeO}_{3}$-based perovskite oxides have high proton conductivity, low chemical stability under acidic (especially for $\mathrm{CO}_{2}$ ) and steam atmospheres is still a great problem $[113,114]$ due to high basic property, giving rise to the decomposition of $\mathrm{BaCeO}_{3}$ to form barium carbonate and barium hydroxide, respectively, as given in Eq.20 and Eq.21.

$$
\begin{gathered}
\mathrm{BaCeO}_{3}+\mathrm{CO}_{2} \rightarrow \mathrm{BaCO}_{3}+\mathrm{CeO}_{2} \\
\mathrm{BaCeO}_{3}+\mathrm{H}_{2} \mathrm{O} \rightarrow \mathrm{Ba}(\mathrm{OH})_{2}+\mathrm{CeO}_{2}
\end{gathered}
$$

For this reason, research interests are towards tailoring $\mathrm{BaCeO}_{3}$-based materials by doping with smaller ionic size to retain high conductivity and endure harsh environments. Substitution $\mathrm{Zr}$ for $\mathrm{Ce}$ is the conventional strategy to show excellent stability to $\mathrm{CO}_{2}$ and $\mathrm{H}_{2} \mathrm{O}$, accompanying with high conductivity [115]. The doping level 
of $40 \mathrm{~mol} \% \mathrm{Zr}$ appears to the best candidate in terms of the tradeoff between the chemical stability and conductivity, as shown in Fig.15(a) [116]. However, the sinterability of Zr-rich $\mathrm{BaCeO}_{3}$-based compounds needs high temperatures ( $c$ a. > $1600{ }^{\circ} \mathrm{C}$ ) due to its refractory nature, leading to small grain sizes and high grain boundaries density. As a result, high resistance of grain boundary shows lower ionic conductivity [117]. $\mathrm{NiO}, \mathrm{CuO}$ and $\mathrm{ZnO}$ are reported to be the most effective sintering aids, most of which accumulate in the grain boundary region, in order to accelerate grain growth and enhance grain boundary conductivity [118, 119]. Indeed, small amounts of $\mathrm{ZnO}$ and $\mathrm{NiO}$, for instance, are proved to slightly incorporate into the perovskite lattice to prevent carbonation under $\mathrm{CO}_{2}$ atmospheres [3, 120, 121]. Compared to $\mathrm{BaCe}_{0.8} \mathrm{Y}_{0.2} \mathrm{O}_{2.9}$ (Fig.15(b)), the increasing $\mathrm{Zr}$ content moderately decreases $\mathrm{CO}_{2}$ sensitivity, but still suffer from carbonation. Further addition of small $\mathrm{ZnO}$ could enhance chemical stability significantly and behave similar to $\mathrm{Zr}$ to stabilize perovskite structure. It is evident that the substitution of In [122], Ga [123] and $\mathrm{Pr}$ [124] dopants with higher electronegativity can improve chemical stability, as well as sinterability. Although the addition of Ga can markedly promote the sinterability of Ydoped $\mathrm{BaZrO}_{3}$, the conductivity is significantly decreased. The light doping of In improves the sinterability moderately, but with a slight decreased conductivity [125]. If further increases In concentration up to $30 \mathrm{~mol} \%$, heavily In-doped $\mathrm{BaZrO}_{3}$ shows a great sinterability and lower bulk conductivity, along with good chemical stability against $\mathrm{CO}_{2}$ and $\mathrm{H}_{2} \mathrm{O}$ [122]. The doping Pr to Y-doped $\mathrm{BaZrO}_{3}$ might be a good candidate to compromise the excellent chemical stability, great sinterability and high proton conductivity for practical applications [124]. Therefore, these dopants can improve the grain boundary sintering, and thus obtain appreciable grain boundary conductivity, but may inevitably decrease the bulk conductivity to some extent. 
(a)

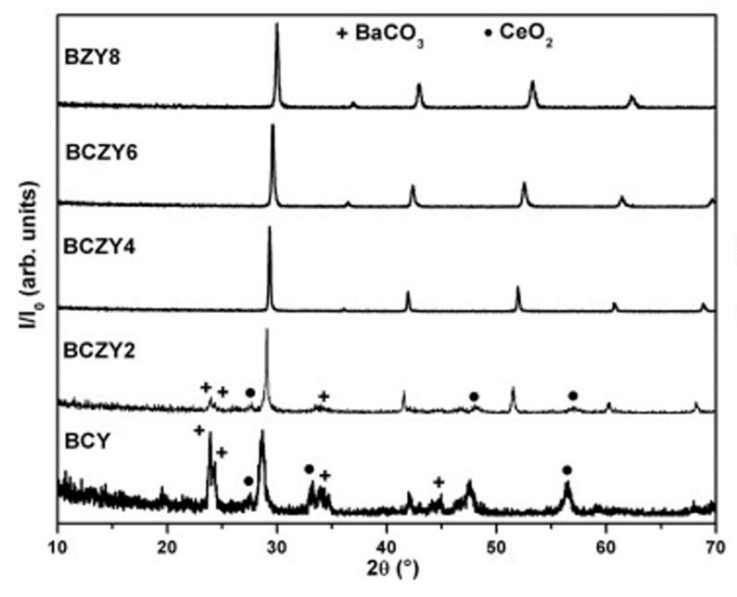

(b)

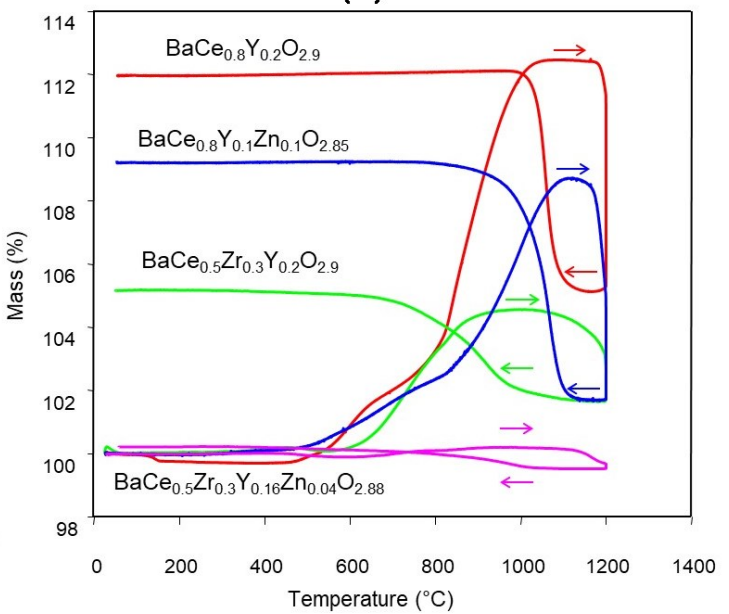

Fig.15. XRD patterns of $\mathrm{BCZY}$ powders after $\mathrm{CO}_{2}$ treatment at $900^{\circ} \mathrm{C}$ [116]. TGA analysis of different compositions in pure $\mathrm{CO}_{2}$, with heating and cooling rate of $5^{\circ} \mathrm{C} / \mathrm{min}[120]$.

As previously noted, water incorporation into the lattice (hydration) through filling into oxygen vacancies to form proton defects for proton transport, is distinct from the behavior of water vapor sensitivity. The induced chemical expansion and weight uptake by hydration process are observed for all proton-conducting oxides during the polymorphic phase transition [126, 127]. Fig.16 shows weight evolution of hydrated and dehydrated $\mathrm{BaCe}_{0.9} \mathrm{Y}_{0.1} \mathrm{O}_{3-\delta}$ investigated by Kruth et al. [128]. It is found that the initial weight loss occurs at the Pbnm to Imma phase transition of $c a .230^{\circ} \mathrm{C}$, where nearly $80 \%$ oxygen vacancies are filled by water. Considering the fact that the significant dehydration is in the phase transition of $R \overline{3} c$ to $P m \overline{3} m$ at $c a .720^{\circ} \mathrm{C}$, the protonic conduction domination transforming to oxygen ions conduction is reported to be in the temperature range of $700-800{ }^{\circ} \mathrm{C}[35]$. That means hydration and dehydration process are closely related to the switch between proton and oxygen ions conduction domination. When in humid atmosphere and low temperatures, most oxygen vacancies occupied by hydroxide ions impede long-range oxygen vacancy migration. In this scenario, the protonic ions formation and diffusion dominate in charge carriers (i.e., high proton conduction shown in this case). Instead, at high temperatures, dehydration from the lattice releases more free oxygen vacancies participating in long-range oxygen ions transport (i.e., mixed ionic conduction shown in this case). Despite lattice expansion during the phase transition, undoped $\mathrm{BaCeO}_{3}$ shows no significant hydration behavior, suggesting the transition may drive the dehydration process. As expected, the 
degree of hydration is strongly correlated to oxygen vacancies in oxides and in linear dependence of Y dopant concentration.

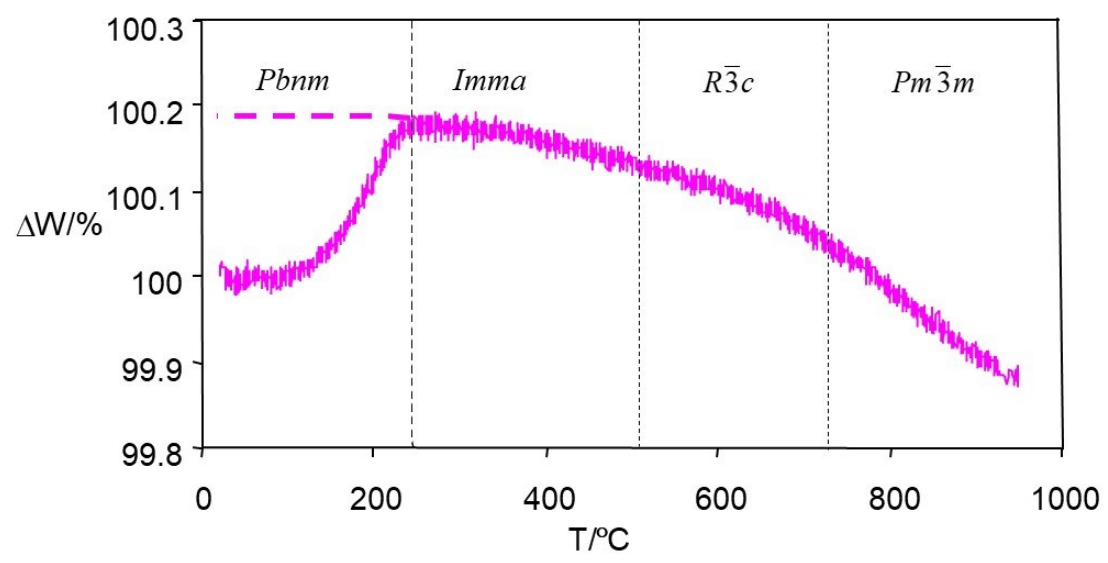

Fig.16. Thermal history of hydrated and dehydrated $\mathrm{BaCe}_{0.9} \mathrm{Y}_{0.1} \mathrm{O}_{3-\delta}$ in wet $5 \% \mathrm{H}_{2} / \mathrm{Ar}$ atmosphere [128].

To our best knowledge, the expansion/ contraction of lattice crystal is heavily associated with hydration/ dehydration process over a wide temperature range. A detailed investigation of thermal behavior in undoped and doped $\mathrm{BaZrO}_{3}$ samples was conducted by Hiraiwa et al. [129], as indicated in Fig.17. When a hydrated sample is heated in a dry atmosphere, the lattice shrinkage occurs due to the dehydration process (Fig.17(a)). When measured in a wet atmosphere again, water-unsaturated lattice can further adsorb water during heating, resulting in the lattice expansion upon heating (Fig.17(b)). In this case, the lattice is unlikely to contract upon dehydration due to in wet conditions. After oxygen vacancies are completely filled by water in second case, the lattice constant retains unchanged upon heating or cooling procedure (Fig.17(c)). When changing to dry atmospheres, the dehydration process occurs again (Fig.17(d)). These abnormal changes in lattice constant suggests proton incorporation can be reversibly manipulated upon heating and cooling treatment, which is induced by the defect equilibrium of protons, oxygen vacancies and other defects that rely on temperature and atmosphere conditions, as in accord with the results of other doped samples $[124,130]$. In contrast to doped $\mathrm{BaZrO}_{3}$, but similar to undoped $\mathrm{BaCeO}_{3}[128]$, undoped $\mathrm{BaZrO}_{3}$ also has no change of lattice expansion and hydration/ dehydration properties with temperature, as shown in Fig.17(e). The abnormal change in lattice constant increases with the increasing Y content up to $20 \mathrm{~mol} \%$ doping level, well in 
agreement with the fact that $20 \mathrm{~mol} \% \mathrm{Y}$ doped $\mathrm{BaZrO}_{3}$ presents the highest proton conductivity [107].
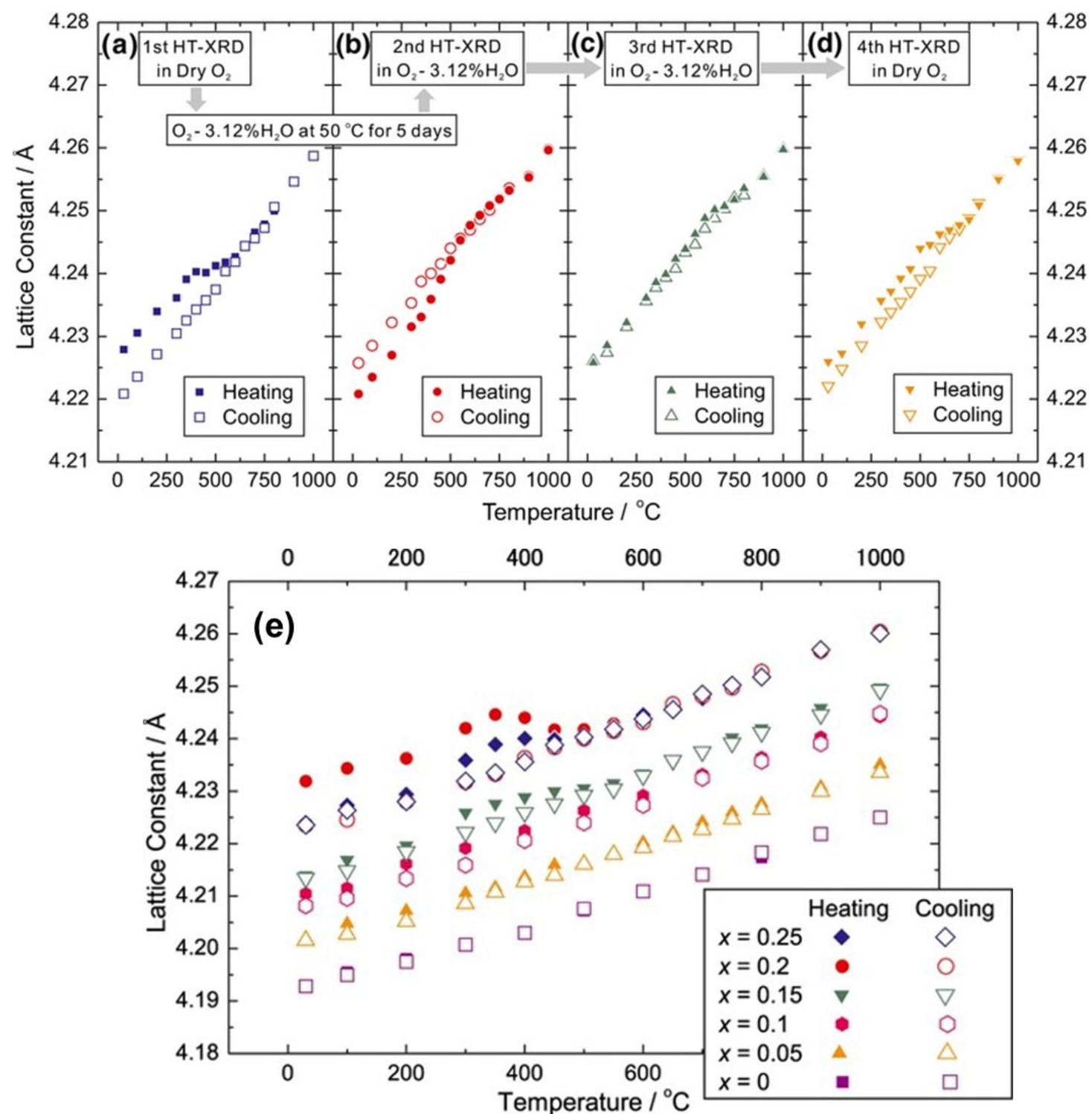

Fig.17. (a-d) The temperature dependence of lattice constant of $\mathrm{BaCe}_{0.8} \mathrm{Y}_{0.2} \mathrm{O}_{3-\delta}$ in dry and wet atmospheres. (e) The temperature dependence of lattice constant of $\mathrm{BaZr}_{1-y} \mathrm{Y}_{y} \mathrm{O}_{3-\delta}(x=0,0.05$, $0.1,0.15,0.2$, and 0.25 ) pellet samples in a dry oxygen atmosphere [129].

\subsection{Catalytic properties (Water gas shift reaction)}

Proton-conducting perovskite oxides are versatile scaffolds as active supports for rare earth and $3 \mathrm{~d}$ transition metal catalysts on the $\mathrm{B}$ site, e.g., $\mathrm{Pt}, \mathrm{Pd}, \mathrm{Ni}, \mathrm{Co}, \mathrm{Cu}, \mathrm{Mn}$ and Fe. These catalytic activities are most likely due to the exsolved nanoparticles upon reduction to enhance heterogenous catalysis on the surface [131]. The strategy of defect chemistry is adopted to explore various catalytic applications, including 
water gas shift reaction, methane reforming and ammonia synthesis. The first two offer the prominent advantage of the separation of hydrogen production (fuel electrode) and water splitting reaction (air electrode). The latter promises a potential enhanced electrochemical synthesis of $\mathrm{N}_{2}$ to $\mathrm{NH}_{3}$ at ambient atmosphere in comparison to conventional Haber-Bosch process $[132,133]$. As limited information is available on catalytic activities of proton conducting oxides in methane reforming and ammonia synthesis, proton conducting oxides prefer to serve as solid state separators [134, 135]. Here we mainly focus upon the (reverse) water gas shift reaction.

The water gas shift (WGS) reaction is reversible and exothermic, as expressed in Eq.22.Typically, the reaction is divided into two-stage processes [136, 137]. At higher temperatures of $310-450{ }^{\circ} \mathrm{C}, \mathrm{Fe} / \mathrm{Cr}$ catalysts are used to increase $\mathrm{CO}$ conversion. In this case, the shift is close to chemical equilibrium, indicating that the reverse water gas shift (RWGS) reaction is most likely to occur. At lower temperatures of $160-250{ }^{\circ} \mathrm{C}$, $\mathrm{Cu} / \mathrm{Zn}$ oxide catalysts are the efficient catalysts to increase $\mathrm{CO}$ conversion.

$$
\mathrm{H}_{2} \mathrm{O}+\mathrm{CO} \leftrightarrow \mathrm{H}_{2}+\mathrm{CO}_{2} \quad \Delta \mathrm{H}_{298 \mathrm{~K}}^{\circ}--41.1 \mathrm{~kJ} / \mathrm{mol}
$$

The incorporation of dense proton-conducting membrane in the WGS reaction can extend the operating temperature up to $700{ }^{\circ} \mathrm{C}$. By driving proton pumping from the anode to cathode side, such as an electrochemical reactor promotes catalytic kinetics of the WGS reaction considerably, which is considered to be a different electrochemical mode from the conventional solid-state proton conductors. In this regard, Li et al. studied hydrogen transport in a tubular $\mathrm{SrCe}_{0.9} \mathrm{Eu}_{0.1} \mathrm{O}_{3-\delta}$ membrane reactor [137]. $\mathrm{He}$ found that the WGS reaction was constrained by thermodynamic equilibrium limitation and the membrane degradation was observed in WGS conditions, due to the unstable cerate structure and catalyst deactivation by carbon deposition. Rajesh et al. [138] argued that Pt-doped $\mathrm{BaCeO}_{3}$ perovskite showed the moderate activity for the WGS reaction, in which oxygen vacancies could be reduced by water dissociation and thus render the membrane proton conductive in the WGS reaction, rather than thermal effects. This discrepancy is ascribed to that Eu metallic nanoparticles are impossible to emerge on the surface of the $\mathrm{SrCe}_{0.9} \mathrm{Eu}_{0.1} \mathrm{O}_{3-\delta}$ membrane, and that Pt nanoparticles can 
be exsolved as a second active site to accelerate the WGS reaction.

Despite the WGS reaction for hydrogen production, the RWGS reaction is favorable at high temperatures, as well as in turn producing $\mathrm{CO}$ from $\mathrm{CO}_{2}$ studied by Viana et al. [139], which can be used as a feedstock for Fischer-Tropsch synthesis. As we can see in Fig.18, BCY10 $\left(\mathrm{BaCe}_{0.9} \mathrm{Y}_{0.1} \mathrm{O}_{2.95}\right)$ exhibits the highest conversion rate but not wellsuited as long-term catalyst in RWGS reaction due to the sensitivity to $\mathrm{H}_{2} \mathrm{O}$ and $\mathrm{CO}_{2}$. When exposed to $\mathrm{H}_{2} / \mathrm{CO}_{2}$ conditions, recent developed $\mathrm{BCN} 18\left(\mathrm{Ba}_{3} \mathrm{Ca}_{1.18} \mathrm{Nb}_{1.82} \mathrm{O}_{8.73}\right.$, belonging to perovskite derivatives, discussed later) is suggested to incorporate water and possible $\mathrm{CO}_{3}^{2-}$ from $\mathrm{CO}_{2}$ into the lattice, achieving a good catalytic performance at high temperatures[140, 141]. While $\operatorname{SCZT}\left(\operatorname{Sr}_{3} \mathrm{CaZr}_{0.5} \mathrm{Ta}_{1.5} \mathrm{O}_{8.75}\right)$ is capable of adsorption of $\mathrm{H}_{2} \mathrm{O}$ and $\mathrm{CO}_{2}$ into the lattice, showing a better conversion rate than the other proton-conducting oxides at low temperatures but declining to $36 \%$ conversion at $900{ }^{\circ} \mathrm{C}$. Lower onset temperature of good performance of SCZT promises an excellent catalytic candidate, most likely due to an easy hydration process at lower temperatures and weakly dependent of the proton conduction of the given electrolyte. Albeit with the increase of proton conduction from water uptake, the consumption of water is reasonable to shift the reaction to left. It should also be noted that $\mathrm{CO}_{2}$ uptake in SCZT and $\mathrm{BCN} 18$ compositions probably provide additional active sites for promoting catalytic properties. In this regard, both $\mathrm{H}_{2} \mathrm{O}$ and $\mathrm{CO}_{2}$ occupancy mechanisms appear to compete to enable the catalytic activity in the RWGS reaction. 


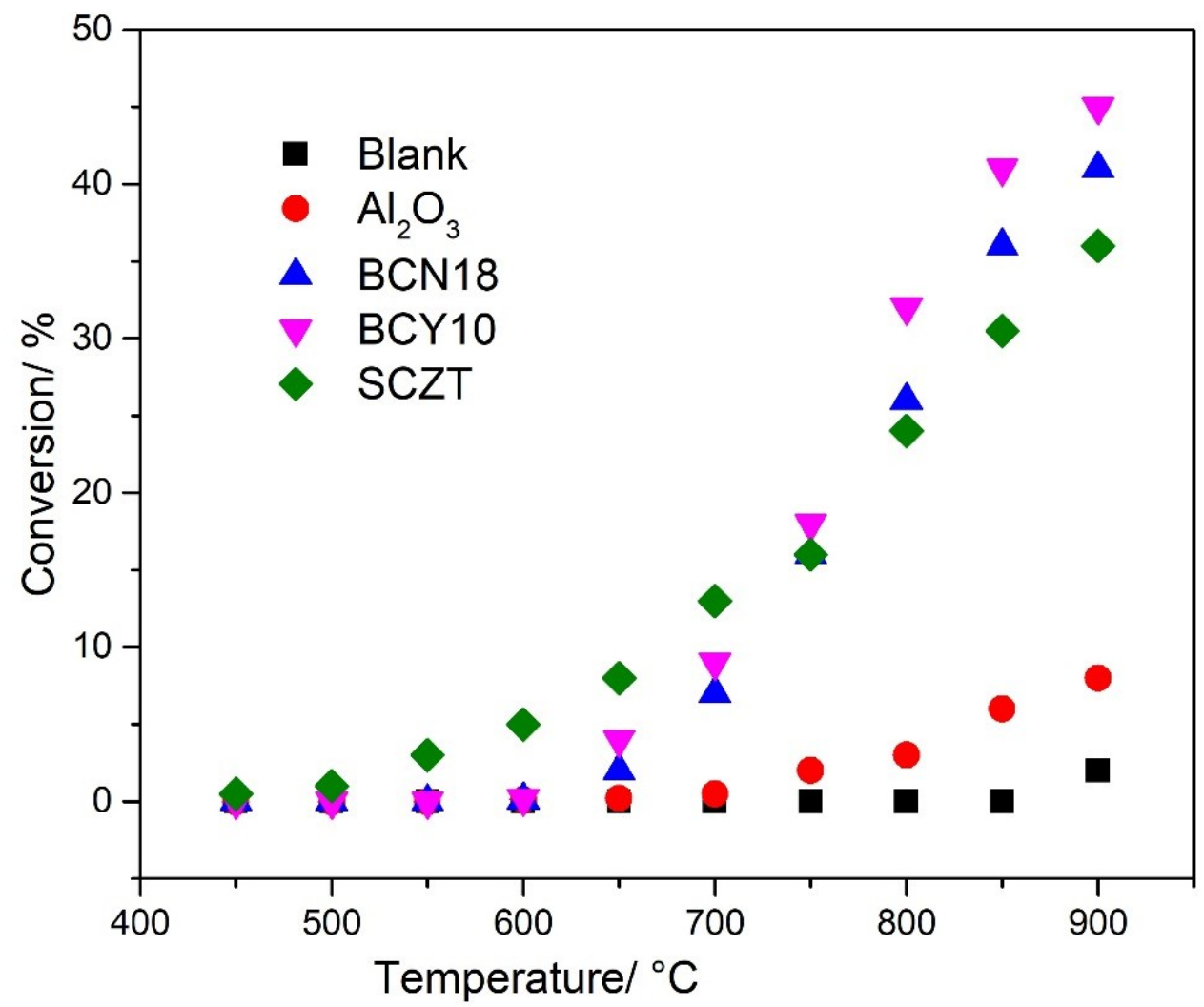

Fig.18. The conversion rate of $\mathrm{CO}_{2}$ to $\mathrm{CO}$ of different proton-conducting oxides and reference membranes [139].

\section{Other related perovskite oxides}

Apart from $\mathrm{A}^{2+} \mathrm{B}^{4+} \mathrm{O}_{3}$ simple perovskite, other types with different charges at $\mathrm{A}$ and $\mathrm{B}$ sites (e.g., $\mathrm{A}^{1+} \mathrm{B}^{5+} \mathrm{O}_{3}, \mathrm{~A}^{3+} \mathrm{B}^{3+} \mathrm{O}_{3}$ ) are also discovered. Early studies of $\mathrm{A}^{1+} \mathrm{B}^{5+} \mathrm{O}_{3}$ perovskites, referring to undoped $\mathrm{KTaO}_{3}$ with an ideal cubic structure of high symmetry $(P m \overline{3} m)$ like $\mathrm{SrTiO}_{3}[142,143]$, show good proton conduction in water vapor conditions. The acceptor dopants $\mathrm{Co}^{2+}, \mathrm{Mn}^{2+}, \mathrm{Cu}^{2+}$, and $\mathrm{Fe}^{3+}$ create oxygen vacancies (formula of $\mathrm{KTa}_{1-x} \mathrm{Me}_{x} \mathrm{O}_{3-x}$ ) and thus form proton defects [144]. Fe-doped composition exhibits the highest proton incorporation compared to other doped potassium tantalate. This is probably due to $\mathrm{Fe}^{3+}$ oxidizing to $\mathrm{Fe}^{4+}\left(\mathrm{Fe}_{\mathrm{Ta}}^{\prime}\right)$ or reducing to $\mathrm{Fe}^{2+}\left(\mathrm{Fe}_{\mathrm{Ta}}^{\prime \prime \prime}\right)$, enabling two distinct local symmetries in the lattice $[145,146]$.

Most $\mathrm{A}^{3+} \mathrm{B}^{3+} \mathrm{O}_{3}$ types exhibit the Pnma orthorhombic structure by octahedral titling towards the [110] and [001] directions of the cubic sublattice [147, 148]. Lanthanumbased perovskite oxides are known to show oxygen ion, proton and electron hole defects dependent on trivalent cations at the $\mathrm{B}$ site. As a result, doped $\mathrm{LaCoO}_{3}$ and 
$\mathrm{LaMnO}_{3}$, for instance, are mixed oxide ion and electron hole conductors. While doped $\mathrm{LaGaO}_{3}$ exhibit pure oxide ion conductivity [149]. It is reported that doped $\mathrm{LaLnO}_{3}$ $(\mathrm{Ln}=\mathrm{Al}, \mathrm{Sc}, \mathrm{In}, \mathrm{Lu}, \mathrm{Er}, \mathrm{Yb}, \mathrm{Y})$ show proton transport domination under wet reducing conditions [150]. Even though the substitution of divalent cations (like $\mathrm{Ca}, \mathrm{Sr}, \mathrm{Ba}$ ) for La can create more oxygen vacancies for proton incorporation [151], the proton conductivity of $\mathrm{A}^{3+} \mathrm{B}^{3+} \mathrm{O}_{3}$-type perovskites is much lower than that of $\mathrm{BaCeO}_{3}$-based proton conductors. Furthermore, such doped $\mathrm{LaLnO}_{3}(\mathrm{Ln}=\mathrm{Al}, \mathrm{Sc}, \mathrm{In}, \mathrm{Lu}, \mathrm{Er}, \mathrm{Yb}, \mathrm{Y})$ have a common tendency that the conductivities decrease with increasing ionic radii of B-site ions, with exception of the mixed ionic conduction of $\mathrm{In}>\mathrm{Sc}(\mathrm{In}=0.80 \AA, \mathrm{Sc}=$ $0.75 \AA$ ). This is probably ascribed to the fact that some oxygen vacancies in local $\mathrm{MO}_{5}$ polyhedral of $\mathrm{La}_{0.9} \mathrm{Sr}_{0.1} \mathrm{ScO}_{3-\delta}$ are structurally stable, not allowing for proton mobility. On the other hand, some oxygen vacancies may be associated with dopants to form dopant-vacancy defects $\left(\left[\mathrm{Sr}_{\mathrm{La}}^{\prime}-\mathrm{V}_{\mathrm{O}}^{\bullet \bullet}-\mathrm{Sr}_{\mathrm{La}}^{\prime}\right]^{\times}\right)$. One possible reason is that the ion size of doped ions should be within a certain range. This means the ion radii shorter or longer than the suitable range might not participate in proton incorporation [150], as well as the consideration of valences of doped ions.

The brownmillerite structured oxide of $\mathrm{Ba}_{2} \mathrm{In}_{2} \mathrm{O}_{5}\left(\mathrm{~A}_{2} \mathrm{BB}^{\prime} \mathrm{O}_{5}\right)$ named after mineral $\mathrm{Ca}_{2} \mathrm{FeAlO}_{5}$ [152], is a derivative of the perovskite structure. It retains orthorhombic Icmm structure from room temperature to $925^{\circ} \mathrm{C}$, shown in Fig. 19 (a), where the twodimensional layers of corner-shared $\mathrm{InO}_{6}$ octahedral and corner-shared $\mathrm{InO}_{4}$ distorted tetrahedral alternate along c-axis, leading to a vacancy of one-sixth of oxygen sites. As a result, there are three distinct oxygen sites in brownmillerite structure: $\mathrm{O}(1)$ in the equatorial plane of the octahedral, $\mathrm{O}(2)$ at the corner-shared sites of the octahedral and tetrahedral, and $\mathrm{O}(3)$ belonging to the equatorial plane of the tetrahedral. Though the concentration of vacancies is in local ordering in tetrahedral planes, this enables $c a$. $16.7 \%$ oxygen vacancies for each formula unit compared to less than $4 \%$ oxygen vacancies in a simple perovskite [36]. These ordering vacancies are relatively immobile and unviable to oxygen transport at lower temperatures, although this does not need to limit proton mobility. From 925 to $1040{ }^{\circ} \mathrm{C}$, the crystallography of $\mathrm{Ba}_{2} \mathrm{In}_{2} \mathrm{O}_{5}$ remains 
tetragonal $14 \mathrm{~cm}$ phase (Fig.19(b)). In this condition, some oxygen vacancies exist in $\mathrm{O}(1)$ and $\mathrm{O}(2)$ sites, not all at $\mathrm{O}(3)$ sites, resulting from $\mathrm{O}(1)-\operatorname{In}(1)-\mathrm{O}(2)$ and $\mathrm{O}(3)-$ $\operatorname{In}(2)-\mathrm{O}(2)$ octahedral tilting. This means oxygen vacancies move from ordering oxygen site $(\mathrm{O}(3))$ to all oxygen sites. Oxygen vacancies are completely distorted until the temperature up to $1040^{\circ} \mathrm{C}$ (the phase transition from tetragonal $14 \mathrm{~cm}$ to cubic $P m \overline{3} m$ phase), indicating oxygen vacancies are free to move at all oxygen sites (Fig.19(c)). However, the temperature of $925^{\circ} \mathrm{C}$ is interpreted to be order-disorder transition due to the disordered oxygen vacancies accommodation, imparting fast oxygen ion conduction [153-156].

(a)

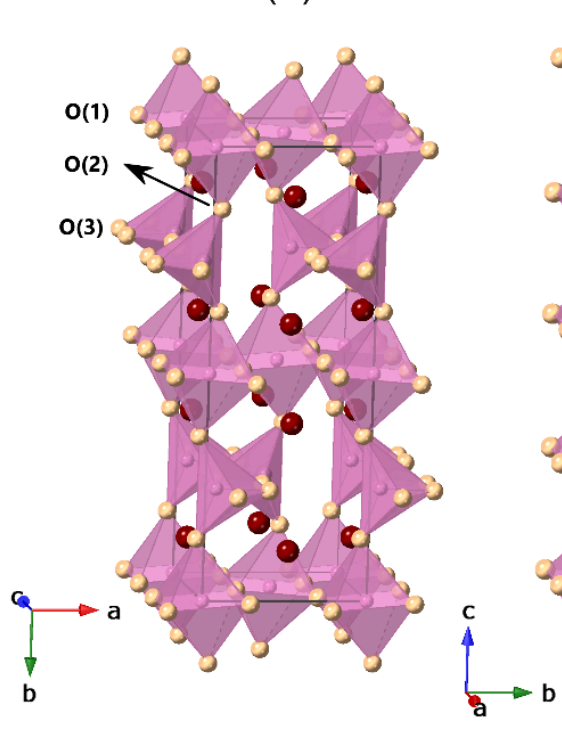

(b)

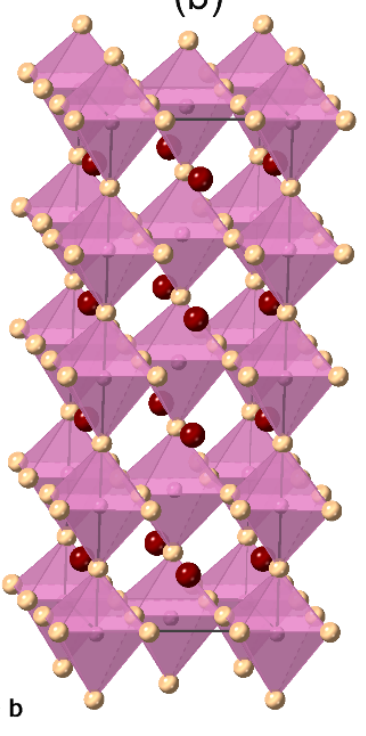

(c)

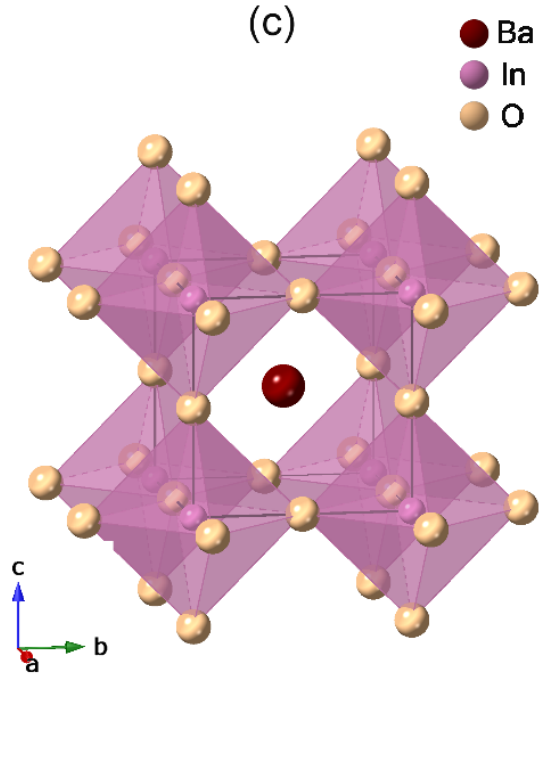

Fig.19. Crystal structures of $\mathrm{Ba}_{2} \operatorname{In}_{2} \mathrm{O}_{5}$ : (a) orthorhombic $I \mathrm{cmm}$, (b) tetragonal $I 4 \mathrm{~cm}$ and (c) cubic $P m \overline{3} m[153]$.

The relationship between structural property and proton conductivity is established when the $\mathrm{Ba}_{2} \mathrm{In}_{2} \mathrm{O}_{5}$ pellet measured in dry and wet air conditions [21]. Three regions can be divided within the operation temperatures in Fig.20. In Region $\mathrm{I}\left(<400^{\circ} \mathrm{C}\right)$, the proton conductivity is dominant in water-saturated atmospheres. The enhanced proton conductivity can be explained by the fact that water incorporation into ordering oxygen vacancies. The formed $\mathrm{Ba}_{2} \mathrm{In}_{2} \mathrm{O}_{5} \cdot \mathrm{H}_{2} \mathrm{O}$ compound facilitates a structure transformation from orthorhombic to tetragonal phase at $320^{\circ} \mathrm{C}$, creating a very high proton content environment at low temperatures [156-158]. The oxide ion conductivity is then gradually significant in total conductivity in Region II $\left(400 \sim 925^{\circ} \mathrm{C}\right)$, where the proton 
conductivity sharply increases at the order-disorder transition temperature, as well as the oxygen ion conductivity. It should be noted that no obvious conductivity change in the tetragonal-to-cubic transition can be corresponding to continuously disordered oxygen vacancies, a characteristic of a lambda transition.

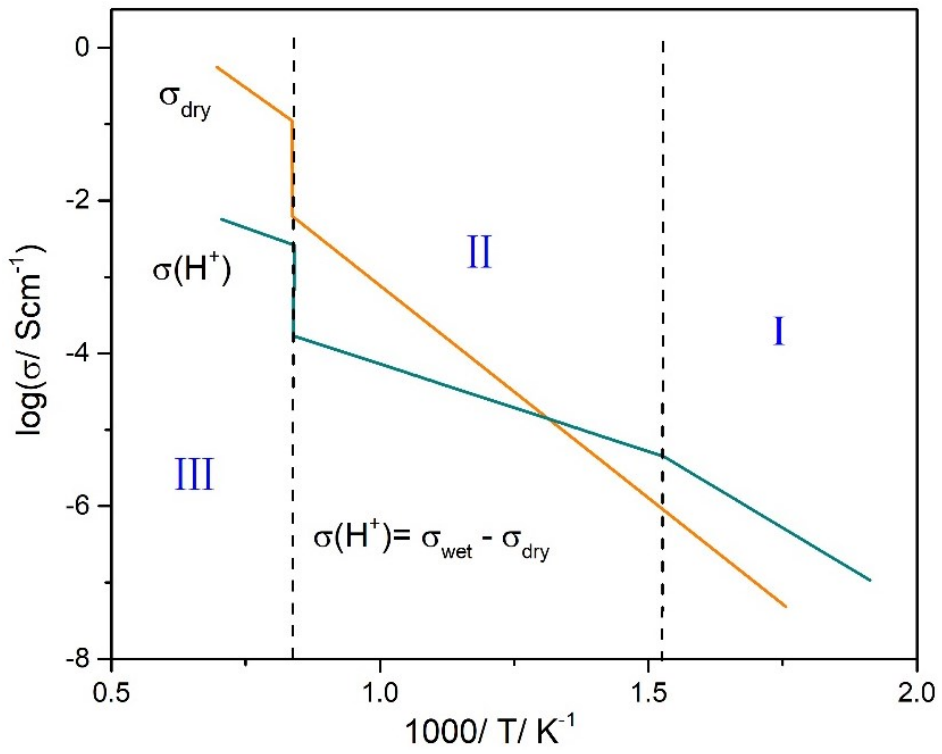

Fig.20. The conductivity of $\mathrm{Ba}_{2} \mathrm{In}_{2} \mathrm{O}_{5}$ in dry and wet air atmospheres [21].

Due to the fact, the strategy of doping at A or B sites is able to stabilize the cubic phase down to lower temperatures to obtain more disordered oxygen vacancies [159161]. This is very important to develop potential proton conductive ceramic materials for application in the intermediate temperature range, apart from $\mathrm{BaCeO}_{3}-\mathrm{BaZrO}_{3}$ systems. For example, the partial substitution of $\mathrm{Sr}^{2+}$ for $\mathrm{Ba}^{2+}$ is not a good choice, which could increase the phase transition temperature and Region II disappears in $\mathrm{Ba}_{1.5} \mathrm{Sr}_{0.5} \mathrm{In}_{2} \mathrm{O}_{5}$ [162]. While the substitution of $\mathrm{Ga}^{3+}$ for $\mathrm{In}^{3+}$ shows a lower orderdisorder transition temperature. When increasing the Ga content, the conductivity in Region III decreases, but the conductivity in Region I increases [159, 163]. Likewise, Ce- and La-doped $\mathrm{Ba}_{2} \mathrm{In}_{2} \mathrm{O}_{5}$ experience this transformation at lower temperatures, but shows several orders of magnitude lower conductivity in hydrogen containing atmosphere compared to undoped $\mathrm{Ba}_{2} \mathrm{In}_{2} \mathrm{O}_{5}$ [164]. These findings reveal that the doping not only enables the orthorhombic to cubic structure to increase the crystal symmetry at low temperatures but also stabilizes the disordered oxygen vacancies of defective perovskite structure. Based on the results, undoped $\mathrm{Ba}_{2} \operatorname{In}_{2} \mathrm{O}_{5}$ may be a promising 
candidate for proton conductors. It should be noted, however, that $\mathrm{Ba}_{2} \mathrm{In}_{2} \mathrm{O}_{5}$ has poor chemical resistance against $\mathrm{CO}_{2}$ or $\mathrm{H}_{2} \mathrm{O}$ atmosphere [165] and readily decomposes above $500^{\circ} \mathrm{C}$ in reducing atmospheres [166], which will impede its electrochemical application for electrolytes.

Alternative non-stoichiometric complex perovskites, formula as $\mathrm{A}_{3} \mathrm{~B}^{\prime}{ }_{1+x} \mathrm{~B}^{\prime \prime}{ }_{2-x} \mathrm{O}_{9-\delta}$ and $\mathrm{A}_{2} \mathrm{~B}^{\prime}{ }_{1+x} \mathrm{~B}^{\prime \prime}{ }_{1-x} \mathrm{O}_{6-\delta}\left(\mathrm{A}=\mathrm{Ba}\right.$ and $\mathrm{Sr}, \mathrm{B}^{\prime \prime}=\mathrm{Ca}, \mathrm{Zn}, \mathrm{Gd}, \mathrm{Nd}, \mathrm{B}=\mathrm{Nb}$ and $\left.\mathrm{Ta}\right)$, are expected to have excellent proton conductivity, which is comparable or superior to that of cerate based perovskites $[23,167]$. Such structure and transport properties are strongly determined by the exact distributions of B-site cations on (111) planes, including 1:2 and 1:1 ordering. From a structural point of view, several studies have investigated the B-site ordering structure due to some inconsistent structural analysis from highresolution neutron or X-ray diffractions [168-170]. In terms of typical composition of $\mathrm{Ba}_{3} \mathrm{Ca}_{1+x} \mathrm{Nb}_{2-x} \mathrm{O}_{9-\delta}(\mathrm{BCN})$, the shift of crystal structure from the two-phase mixture of $1: 1$ and $1: 2$ ordering to pure $1: 1$ ordered phase is verified by X-ray diffractions on basis of $F m \overline{3} m$ space group [170,171]. From Fig 21(a), the 1:2 ordered unit cell consists of three perovskite units along [111] directions, in which $\mathrm{Nb}$ ions accommodate two of three, and Ca ions occupy the third (111) plane in a cubic closed pack cell of Ba cations. In a 1:1 ordered cubic cell (Fig.21(b)), Nb ions occupy a plane perpendicular to [111] directions and in other planes $\mathrm{Nb}$ and $\mathrm{Ca}$ ions are accommodated randomly. For -0.03 $\leq x \leq 0.03$, the crystal structure shows $1: 2$ ordering at the B sites with rhombohedral $P \overline{3} m 1$ symmetry. Further increasing $x$ to $0.09,1: 1$ ordered phase $(F m \overline{3} m)$ appears and two ordering phases coexist in compositional region of $0.09 \leq x \leq 0.24$. That implies that the structure of $\mathrm{Ba}_{3} \mathrm{Ca}_{1+x} \mathrm{Nb}_{2-x} \mathrm{O}_{9-\delta}$ gradually transforms from rhombohedral to cubic phase $0 \leq x \leq 0.24$. They also considered the broad phase transition was due to local structural change induced by large valence and ion radius difference $\left(\mathrm{Ca}^{2+}: 1.14 \AA\right.$ and $\mathrm{Nb}^{5+}: 0.78 \AA$ ). However, considering the relationship between the ion radii of B-site cations and the variations of bond lengths and polyhedral volumes of $\left[\mathrm{BO}_{6}\right]$ octahedral, Oikawa et al. [169] argued that the most suitable setting was found to be rhombohedral $R \overline{3} m$ space group and the two-phase mixture was not detected in all compositions $(x=$ $0.10,0.18,0.25,0.35)$. To more precisely confirm the structure of $\mathrm{Ba}_{3} \mathrm{Ca}_{1+x} \mathrm{Nb}_{2-x} \mathrm{O}_{9-\delta}$, 
Singh et al. [172] revisited the structural properties with $F m \overline{3} m$ and $R \overline{3} m$ settings in a wide range of $\mathrm{Ca} / \mathrm{Nb}$ ratio $(x=0,0.09,0.18,0.27,0.36,0.45)$ by combined synchrotron X-ray and neutron (time-of-flight) diffractions. Over all compositions, both $F m \overline{3} m$ and $R \overline{3} m$ space groups could be used to simulate the X-ray and neutron diffractions due to A-site and B-site cations occupying in very similar environments. As expected, no twophase mixture exists in the composition of $\mathrm{Ba}_{3} \mathrm{CaNb}_{2} \mathrm{O}_{9}$. However, on basis of $F m \overline{3} m$ model, two-phase mixture increases with $x$ from $1.3 \%$ for $x=0.18$ to $7.3 \%$ for $x=0.45$. Surprisingly, $P \overline{3} \mathrm{ml}$ model could not be suited for all compositions, even for $\mathrm{Ba}_{3} \mathrm{CaNb}_{2} \mathrm{O}_{9}$. This suggests that 1:2 ordering may not be in crystal structure. Further evidence indicates ordering phase is dependent on synthesis conditions. That is, such perovskites may undergo structural ordering transitions with temperature ramping and annealing processing, probably localizing domains of different structure ordering on a nanoscale. For example, $\mathrm{Ba}_{3} \mathrm{CaNb}_{2} \mathrm{O}_{9}$ can fully crystallize in $P \overline{3} m 1$ at $1500{ }^{\circ} \mathrm{C}$ for $32 \mathrm{~h}$ and $F m \overline{3} m$ at $1600{ }^{\circ} \mathrm{C}$ at $2 \mathrm{~h}$, respectively [173]. Some observations also occur in doped niobate, $\mathrm{BaCa}_{0.335} \mathrm{M}_{0.165} \mathrm{Nb}_{0.5} \mathrm{O}_{3-\delta}(\mathrm{M}=\mathrm{Mn}, \mathrm{Fe}, \mathrm{Co})$. It crystallizes in $P m \overline{3} m$ structure at $900{ }^{\circ} \mathrm{C}$, and then transforms to B-site $2: 1$ ordering perovskite $(P \overline{3} \mathrm{ml})$ at $1200{ }^{\circ} \mathrm{C}$, eventually converts into B-site $1: 1$ ordering phase at $1300{ }^{\circ} \mathrm{C}$ [174]. Indeed, more investigations need to be conducted to clarify the B-site ordering evolution in terms of chemical compositions and synthesis conditions.

(a)

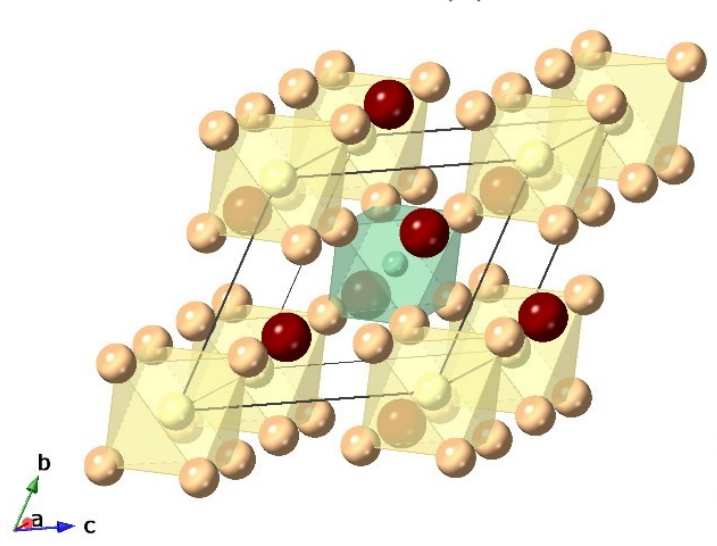

(b)

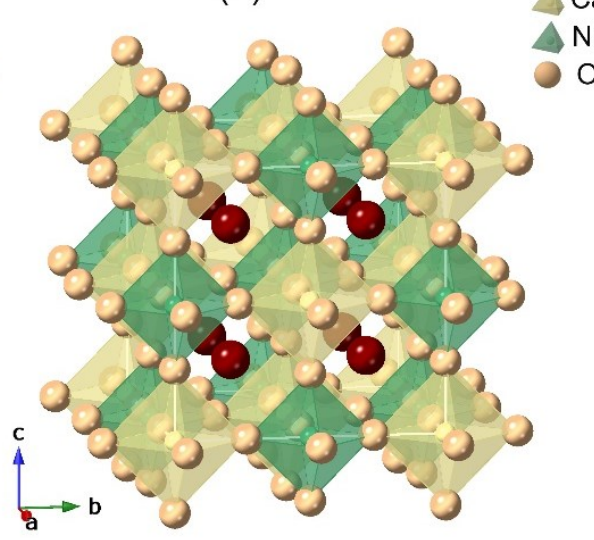

Fig.21. Structures of $\mathrm{A}_{3} \mathrm{~B}^{\prime}{ }_{1+x} \mathrm{~B}{ }_{2-x} \mathrm{O}_{9-8}$ : (a) 1:2 type $\mathrm{B}$-site ordered trigonal unit cell and (b) 1:1 type $\mathrm{B}$-site ordered cubic unit cell.

Similar to other perovskites, stoichiometric compositions show negligible proton 
conductivity due to lack of oxygen vacancies. When substituting $\mathrm{Ca}^{2+}$ with lower valence for $\mathrm{Nb}^{5+}$, oxygen vacancies are created by the compensation for negatively charged $\mathrm{Ca}_{\mathrm{Nb}}^{\prime \prime \prime}$, as described by Eq. 23. From water uptake measurement, only about $1 / 3$ oxygen vacancies are filled by proton in BCN compositions, while nearly $80 \%$ of oxygen vacancies are absorbed in cerate based perovskites [171].

$$
3 \mathrm{O}_{\mathrm{O}}^{\times}+2 \mathrm{CaO}+2 \mathrm{Nb}_{\mathrm{Nb}}^{\times} \rightarrow 2 \mathrm{Ca}_{\mathrm{Nb}}^{\prime \prime \prime}+3 \mathrm{~V}_{\mathrm{O}}^{\bullet \bullet}+\mathrm{Nb}_{2} \mathrm{O}_{5}
$$

As a result, BCN18 composition is demonstrated to be the highest oxide ion conduction but show slightly lower conductivity compared to other compositions under a humid atmosphere (Fig.22). For higher $\mathrm{Ca} / \mathrm{Nb}$ ratio, the reduced conductivity can be explained from two aspects: (1) the disappearance of 1:2 ordered structure releases more random oxygen vacancies in 1:1 ordered cubic phase; (2) negative $\mathrm{Ca}_{\mathrm{Nb}}^{\prime \prime \prime}$ defects can trap oxygen vacancies $\mathrm{V}_{\mathrm{O}}^{\bullet \bullet}$ to form defect-dopant associations (such as $\left[\mathrm{V}_{\mathrm{O}}^{\bullet \bullet}-\mathrm{Ca}_{\mathrm{Nb}}^{\prime \prime \prime}\right]^{\prime}$, , and the ordered $\mathrm{V}_{\mathrm{O}}^{\bullet \bullet}$ are not available to proton and oxide ion conduction, as similar explanation for other perovskites. In addition, $\mathrm{BCN}$ is much more stable than $\mathrm{BaCeO}_{3}-\mathrm{BaZrO}_{3}$ systems when exposed to $\mathrm{CO}_{2}$ and humid atmospheres and has no hole conduction in oxidizing atmospheres up to $900{ }^{\circ} \mathrm{C}$ due to the presence of wide band gap in energy band $[140,141]$. Similar to $\mathrm{BaCeO}_{3}-\mathrm{BaZrO}_{3}$ systems, however, the sinterability of $\mathrm{BCN}$ is relatively poor, which requires a high sintering temperature $\left(1600{ }^{\circ} \mathrm{C}\right)$ to densify the $\mathrm{BCN}$ electrolyte. Due to the limitation of proton concentration, substitutions of cations with lower valences, such as $\mathrm{Ti}$ [175], Ce [176], $\mathrm{Y}$ [141], $\mathrm{Zr}$ [177] can introduce more oxygen vacancies and manipulate the ordering phase at the $\mathrm{B}$ site. $\mathrm{Ba}_{3} \mathrm{Ca}_{1.18} \mathrm{Nb}_{1.52} \mathrm{Y}_{0.3} \mathrm{O}_{9-\delta}$ shows the highest conductivity among all doped compositions.

A detailed study of $\mathrm{Ba}_{3} \mathrm{Ca}_{1+x} \mathrm{Ta}_{2-x} \mathrm{O}_{9-3 / 2 x}(\mathrm{BCT}, x=0.18)$, chemically and structurally similar to BCN analogue, was conducted by Irvine et al. [168, 178, 179]. The neutron and X-ray diffractions indicate that 1:1 ordered cubic phase is the main phase in BCT systems. It is further evident that synthesis procedure plays a critical role in B-site ordering, determining the phase ratio and local compositional distribution. For 
example, the phase ratio of $1: 2$ and $1: 1$ ordering is $15 / 85$ at the sintering temperature of $1450{ }^{\circ} \mathrm{C}$, and increase to $50 / 50$ at $1500{ }^{\circ} \mathrm{C}$. It also implies that the B-site ordering allows $\mathrm{CO}_{2}$ occupying oxygen vacancies to form carbonate ion defects or coupling with other defects to form association defects, rather than forming carbonate species on the surface or stuck in grain boundaries. In case of Zr-doped compositions [179], the lattice can accommodate excess water, oxygen and carbon dioxide without any loss of ordered perovskite. Approximately 55\% of oxygen vacancies are filled by water in the lattice, showing an improvement in conductivity compared to BCN18. However, higher gain boundary resistances are unfavorable in practical applications.

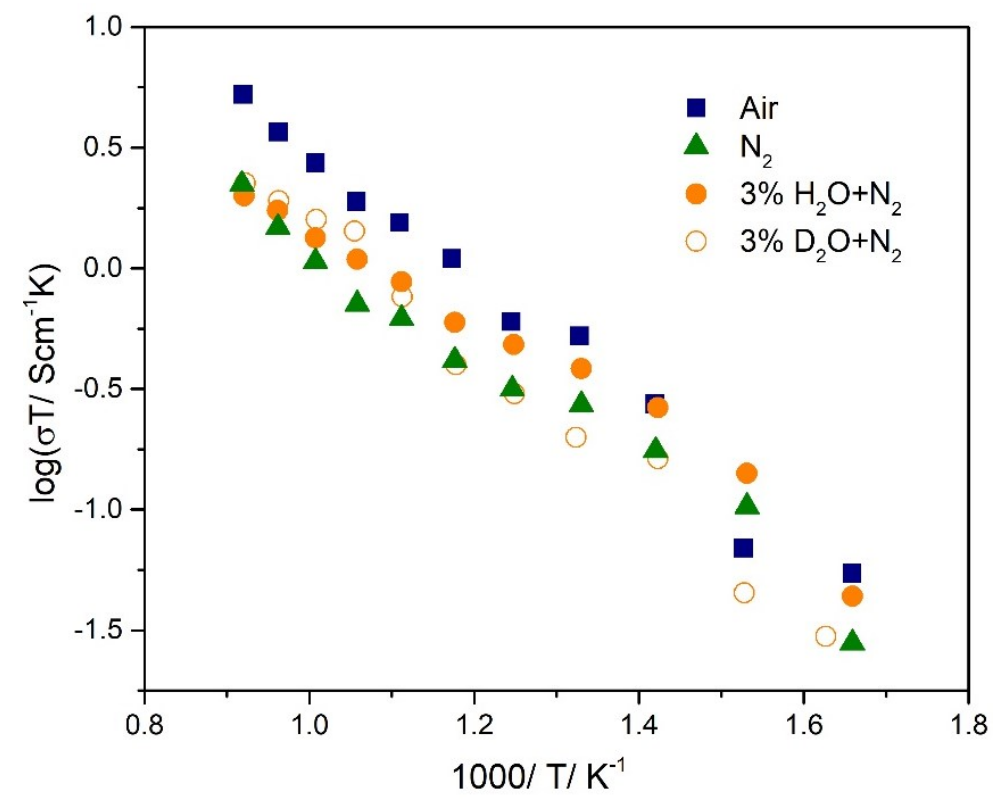

Fig.22. Arrhenius plots of total conductivities of BCN18 under different atmospheres [172].

\section{Overview}

Following the aforementioned discussion, total conductivities of state-of-the-art oxygen oxide and proton conductors are compared in Fig.23 to screen the best promising candidate for practical applications to date. It is generally accepted that the ionic conductivity of the electrolyte should be more than $0.01 \mathrm{Scm}^{-1}$ for its practical electrolyte in fuel cells. Obviously, the proton conducting perovskite oxides highlight significantly superior conductivity than other conventional solid-state conductors in the intermediate temperature range, especially for highly textured BZY films that can be achieved by PLD processing [180]. Despite the comparable conductivity of Ni-doped BCN18 in comparison to some BCZY compositions, as well as excellent chemical 
tolerance against $\mathrm{H}_{2} \mathrm{O}$ and $\mathrm{CO}_{2}$, the use of the electrolyte is unviable due to low power output in fuel cells [181]. Besides, thermal cycling, redox tolerance, thermal expansion coefficient (TEC) and chemical combability with the electrode are required to consider. Very recently, the newly developed hexagonal perovskite $\mathrm{Ba}_{7} \mathrm{Nb}_{4} \mathrm{MoO}_{20}$ with high oxygen ion and proton conductivity show excellent chemical and electric stability [182]. Further work as a dual-ion electrolyte in a ceramic fuel cell is anticipated. In fact, the most common protonic ceramic electrolyte tends to converge towards BCZY series, for which Yb-doped BCZY compositions offer an excellent balance of performance, stability, cost and fabrication $[105,183]$. For this reason, we aim to build strategies to maximize proton conduction by careful tailoring and control of non-stoichiometry of the electrolyte, understanding the correlation of defect chemistry and transport properties, optimizing manufacturing parameters and adjusting operating conditions.

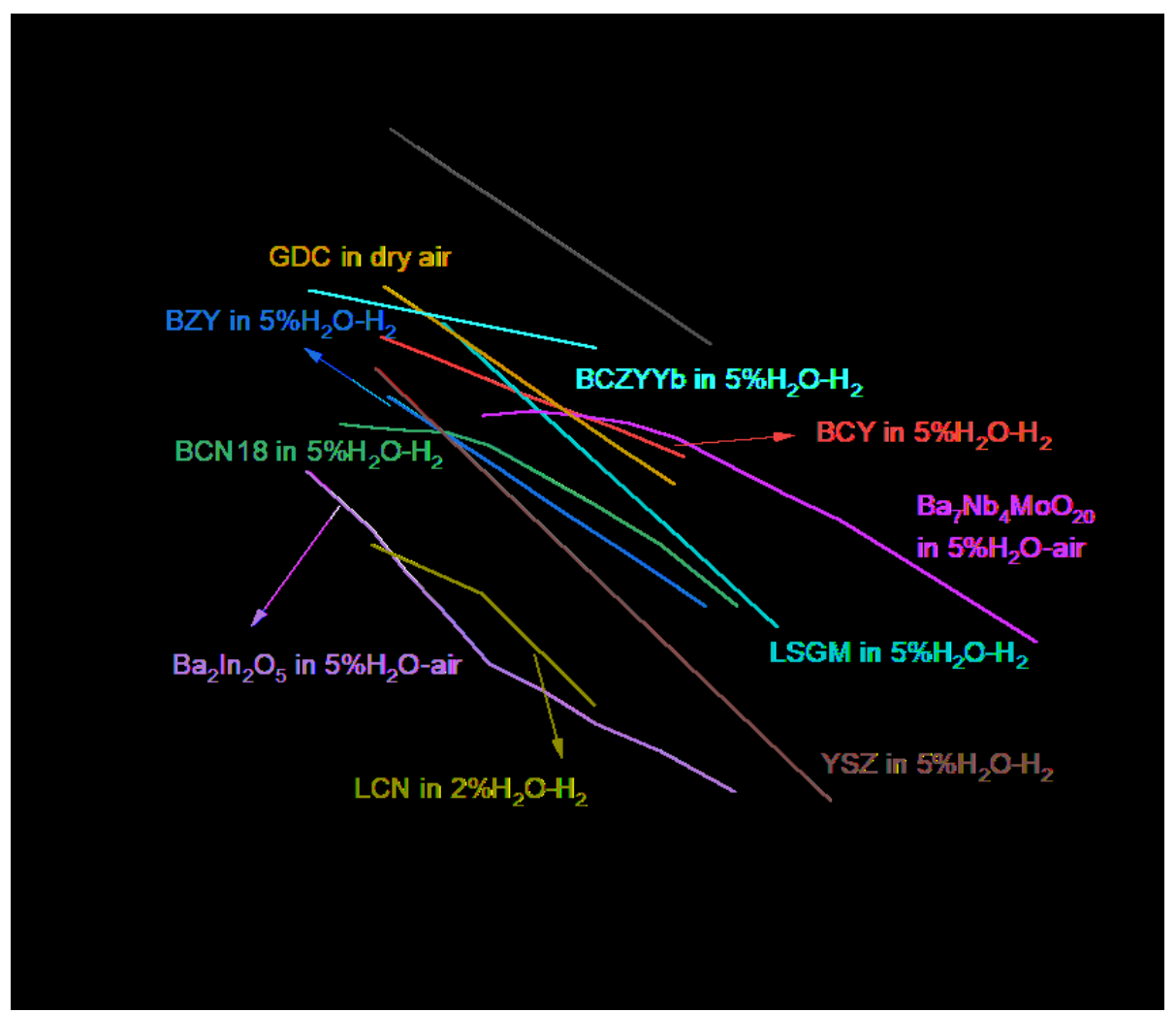

Fig.23. Arrhenius plots of total conductivities of state-of-the-art oxygen oxide and proton conductors: $\mathrm{BaZr}_{0.8} \mathrm{Y}_{0.2} \mathrm{O}_{3-\delta}$ (BZY) films [180], $\mathrm{BaZr}_{0.8} \mathrm{Y}_{0.2} \mathrm{O}_{3-\delta}$ (BZY) and $\mathrm{BaCe}_{0.8} \mathrm{Y}_{0.2} \mathrm{O}_{3-\delta}(\mathrm{BCY})$ [184], $\mathrm{BaCe}_{0.7} \mathrm{Zr}_{0.1} \mathrm{Y}_{0.1} \mathrm{Yb}_{0.1} \mathrm{O}_{3-\delta}$ (BCZYYb) [185], $\mathrm{Ba}_{3} \mathrm{Ca}_{1.18} \mathrm{Nb}_{1.82} \mathrm{O}_{9-\delta}$ (BCN18) [176], $\mathrm{Ba}_{2} \mathrm{In}_{2} \mathrm{O}_{5}$ [21], $\mathrm{Ba}_{7} \mathrm{Nb}_{4} \mathrm{MoO}_{20}$ [182], $\mathrm{La}_{0.99} \mathrm{Ca}_{0.01} \mathrm{NbO}_{4}$ (LCN) [30], $\mathrm{La}_{0.8} \mathrm{Sr}_{0.2} \mathrm{Ga}_{0.2} \mathrm{Mg}_{0.2} \mathrm{O}_{3-\delta}$ (LSGM)[186], $\mathrm{Ce}_{0.8} \mathrm{Gd}_{0.2} \mathrm{O}_{2-\delta}$ (GDC) [187], $\mathrm{Zr}_{0.92} \mathrm{Y}_{0.08} \mathrm{O}_{1.96}$ (YSZ) [188].

\section{Conclusion}


Oxides with perovskite-type structures show great potential in proton-conducting applications. Recent advances of defect chemistry have been focused on simple $\mathrm{A}^{2+} \mathrm{B}^{4+} \mathrm{O}_{3}$ perovskites $\left(\mathrm{BaCeO}_{3}-\mathrm{BaZrO}_{3}\right.$ system $)$, as well as disordered $\left(\mathrm{A}^{1+} \mathrm{B}^{5+} \mathrm{O}_{3}\right.$ and $\left.\mathrm{A}^{3+} \mathrm{B}^{3+} \mathrm{O}_{3}\right)$, and new derivative perovskites $\left(\mathrm{A}_{2} \mathrm{BB}^{\prime} \mathrm{O}_{5}\right.$ and $\left.\mathrm{A}_{3}\left(\mathrm{BB}_{2}{ }_{2}\right) \mathrm{O}_{9}\right)$. The strategy of A- and B-site non-stoichiometry on parent perovskites control over structure, chemical stability, transport and catalytic properties, inclusion of the creation of oxygen vacancies to enable proton incorporation and transport but associated with undesired mixed oxygen ion, hole conduction and defect association. A deep understanding of composition-structure-property relationships should be further established to guide the far-reaching development of proton conducting perovskite conductors. Due to unsatisfying proton conduction at much lower temperatures $\left(<400{ }^{\circ} \mathrm{C}\right)$ achieved on current technologies, innovative solid-sate perovskite materials are urgent to be sought, providing new prospects for the near-future application.

\section{Acknowledgement}

We appreciate that EPSRC-EP/P007821/1 and LERG for funding support.

\section{Reference}

[1] K.D. Kreuer, Annu Rev Mater Res 33 (2003) 333.

[2] W. Zajac, D. Rusinek, K. Zheng, J. Molenda, Cent Eur J Chem 11 (2013) (4) 471.

[3] C. Duan, J. Huang, N. Sullivan, R. O'Hayre, Applied Physics Reviews 7 (2020) (1) 011314.

[4] B. Singh, S. Ghosh, S. Aich, B. Roy, Journal of Power Sources 339 (2017) 103.

[5] J. Basbus, M. Arce, H. Troiani, Q. Su, H. Wang, A. Caneiro, L. Mogni, International Journal of Hydrogen Energy 45 (2020) (8) 5481.

[6] F. Wang, Y. Lyu, D. Chu, Z. Jin, G. Zhang, D. Wang, Materials Science and Technology 35 (2019)

(13) 1551.

[7] E.C.C.d. Souza, R. Muccillo, Materials Research 13 (2010) 385.

[8] Z. Lei, J. Jing, J. Pang, R. Hu, X. Shi, Z. Yang, S. Peng, International Journal of Hydrogen Energy 45 (2020) (15) 8041.

[9] V. Kyriakou, I. Garagounis, E. Vasileiou, A. Vourros, M. Stoukides, Catalysis Today 286 (2017) 2. [10] S.H. Morejudo, R. Zanón, S. Escolástico, I. Yuste-Tirados, H. Malerød-Fjeld, P.K. Vestre, W.G. Coors, A. Martínez, T. Norby, J.M. Serra, C. Kjølseth, Science 353 (2016) (6299) 563.

[11] E. Ruiz-Trejo, J.T.S. Irvine, Solid State Ionics 216 (2012) 36.

[12] L. Gan, L. Ye, S. Wang, M. Liu, S. Tao, K. Xie, International Journal of Hydrogen Energy 41 (2016)

(2) 1170 .

[13] N. Bausá, S. Escolástico, J.M. Serra, J Co2 Util 34 (2019) 231.

[14] J.W. Phair, S.P.S. Badwal, Ionics 12 (2006) (2) 103. 
[15] Y. Tong, Y. Wang, C. Cui, S. Wang, B. Xie, R. Peng, C. Chen, Z. Zhan, Journal of Power Sources 457 (2020) 228036.

[16] A. Kalyakin, A. Volkov, J. Lyagaeva, D. Medvedev, A. Demin, P. Tsiakaras, Sensors and Actuators B: Chemical 231 (2016) 175.

[17] E. Juhera, M. Calvet, A. Revuelta, J. Abellà, S. Colominas, Fusion Engineering and Design 146 (2019) 2066.

[18] H. Iwahara, Solid State Ionics 86-88 (1996) 9.

[19] T. Scherban, A.S. Nowick, Solid State Ionics 53-56 (1992) 1004.

[20] D. Lybye, F.W. Poulsen, M. Mogensen, Solid State Ionics 128 (2000) (1) 91.

[21] G.B. Zhang, D.M. Smyth, Solid State Ionics 82 (1995) (3) 153.

[22] A.S. Nowick, K.C. Liang, Solid State Ionics 129 (2000) (1) 201.

[23] K.C. Liang, Y. Du, A.S. Nowick, Solid State Ionics 69 (1994) (2) 117.

[24] A.S. Nowick, Y. Du, Solid State Ionics 77 (1995) 137.

[25] K.D. Kreuer, Solid State Ionics 136 (2000) 149.

[26] K.S. Knight, N. Bonanos, Solid State Ionics 232 (2013) 112.

[27] N.I. Matskevich, Journal of Thermal Analysis and Calorimetry 90 (2007) (3) 955.

[28] Y. Zhou, X. Guan, H. Zhou, K. Ramadoss, S. Adam, H. Liu, S. Lee, J. Shi, M. Tsuchiya, D.D. Fong, S. Ramanathan, Nature (2016).

[29] V. Besikiotis, C.S. Knee, I. Ahmed, R. Haugsrud, T. Norby, Solid State Ionics 228 (2012) 1.

[30] R. Haugsrud, T. Norby, Nature Materials 5 (2006) (3) 193.

[31] K.-D. Kreuer, S.J. Paddison, E. Spohr, M. Schuster, Chemical Reviews 104 (2004) (10) 4637.

[32] D. Medvedev, A. Murashkina, E. Pikalova, A. Demin, A. Podias, P. Tsiakaras, Prog Mater Sci 60 (2014) 72 .

[33] D. Medvedev, J. Lyagaeva, E.V. Gorbova, A. Demin, P. Tsiakaras, Advanced materials for SOFC application: Strategies for the development of highly conductive and stable solid oxide proton electrolytes (2016).

[34] M. Marrony, P. Pan Stanford, Proton-conducting ceramics from fundamentals to applied research, Pan Stanford Publishing, Singapore (2016).

[35] N. Bonanos, K.S. Knight, B. Ellis, Solid State Ionics 79 (1995) 161.

[36] N. Kochetova, I. Animitsa, D. Medvedev, A. Demin, P. Tsiakaras, Rsc Advances 6 (2016) (77) 73222.

[37] J. Kim, S. Sengodan, S. Kim, O. Kwon, Y. Bu, G. Kim, Renewable and Sustainable Energy Reviews 109 (2019) 606.

[38] D. Neagu, J.T.S. Irvine, Comprehensive Inorganic Chemistry II, Elsevier (2013), p.397-415.

[39] C. J. Bartel, C. Sutton, B. Goldsmith, R. Ouyang, C. Musgrave, L. Ghiringhelli, M. Scheffler, New Tolerance Factor to Predict the Stability of Perovskite Oxides and Halides (2019).

[40] A.M. Glazer, Acta Crystallogr B Struct Crystallogr Cryst Chem Acta Crystallographica Section B Structural Crystallography and Crystal Chemistry 28 (1972) (11) 3384.

[41] A.M. Glazer, Acta Cryst A Acta Crystallographica Section A 31 (1975) (6) 756.

[42] A. Kruth, R.A. Davies, M.S. Islam, J.T.S. Irvine, Chem Mater 19 (2007) (6) 1239.

[43] M. Cwik, T. Lorenz, J. Baier, R. Müller, G. André, F. Bourée, F. Lichtenberg, A. Freimuth, R. Schmitz, E. Müller-Hartmann, M. Braden, Physical Review B 68 (2003) (6) 060401.

[44] K.S. Knight, Solid State Ionics 74 (1994) (3) 109.

[45] K.S. Knight, Solid State Ionics 145 (2001) (1) 275.

[46] A. Kruth, G.C. Mather, J.R. Jurado, J.T.S. Irvine, Solid State Ionics 176 (2005) (7) 703. 
[47] C.J. Howard, H.T. Stokes, Acta Crystallographica Section B 54 (1998) (6) 782.

[48] A.R. Akbarzadeh, I. Kornev, C. Malibert, L. Bellaiche, J.M. Kiat, Physical Review B 72 (2005) (20) 205104.

[49] A. Perrichon, E. Jedvik Granhed, G. Romanelli, A. Piovano, A. Lindman, P. Hyldgaard, G. Wahnström, M. Karlsson, Chem Mater 32 (2020) (7) 2824.

[50] F. Giannici, M. Shirpour, A. Longo, A. Martorana, R. Merkle, J. Maier, Chem Mater 23 (2011) (11) 2994.

[51] W. Münch, K.D. Kreuer, Adams, G. Seifert, J. Maier, Phase Transitions 68 (1999) (3) 567.

[52] D. Shima, S.M. Haile, Solid State Ionics 97 (1997) (1) 443.

[53] S.M. Haile, G. Staneff, K.H. Ryu, Journal of Materials Science 36 (2001) (5) 1149.

[54] G. Ma, H. Matsumoto, H. Iwahara, Solid State Ionics 122 (1999) (1) 237.

[55] S. M. Haile, G. Staneff, K. H. Ryu, Non-Stoichiometry, Grain Boundary Transport and Chemical Stability of Proton Conducting Perovskites (2001).

[56] K.D. Kreuer, E. Schönherr, J. Maier, Solid State Ionics 70-71 (1994) 278.

[57] J. Wu, L.P. Li, W.T.P. Espinosa, S.M. Haile, J Mater Res 19 (2004) (8) 2366.

[58] J. Wu, Defect chemistry and proton conductivity in Ba-based perovskites, California Institute of Technology (2005).

[59] C. Zhang, H. Zhao, Materials Research Bulletin 45 (2010) (11) 1659.

[60] C. Jin, Z. Huizhu, D. Lei, L. Yuehua, L. Wang, Ceramics International 41 (2015) (6) 7796.

[61] Y. Yamazaki, R. Hernandez-Sanchez, S.M. Haile, Journal of Materials Chemistry 20 (2010) (37) 8158.

[62] G.C. Mather, F.M. Figueiredo, J. Romero de Paz, S. García-Martín, Inorg Chem 47 (2008) (3) 921.

[63] G.C. Mather, S. García-Martín, D. Benne, C. Ritter, U. Amador, Journal of Materials Chemistry 21 (2011) (15) 5764.

[64] A. Kruth, G. Mather, J. Ramón Jurado, J. Irvine, Anomalous variations of unit cell parameters with composition in proton conducting, ACeO3-type perovskite solid solutions (2005).

[65] K.S. Knight, Solid State Commun 112 (1999) (2) 73.

$[66]$

[67] K.S. Knight, Solid state communications. 112 (1999) (2) 73.

[68] K.S. Knight, M. Soar, N. Bonanos, Journal of Materials Chemistry 2 (1992) (7) 709.

[69] K. Takeuchi, C.K. Loong, J.W. Richardson, J. Guan, S.E. Dorris, U. Balachandran, Solid State Ionics 138 (2000) (1) 63.

[70] K.D. Kreuer, S. Adams, W. Münch, A. Fuchs, U. Klock, J. Maier, Solid State Ionics 145 (2001) (1) 295.

[71] K.S. Knight, N. Bonanos, Materials Research Bulletin 30 (1995) (3) 347.

[72] M. Amsif, D. Marrero-Lopez, J.C. Ruiz-Morales, S.N. Savvin, M. Gabás, P. Nunez, Journal of Power Sources 196 (2011) (7) 3461.

[73] N. Bonanos, B. Ellis, K.S. Knight, M.N. Mahmood, Solid State Ionics 35 (1989) (1) 179.

[74] E. Gorbova, V. Maragou, D. Medvedev, A. Demin, P. Tsiakaras, Journal of Power Sources 181 (2008) (2) 207.

[75] H. Iwahara, T. Yajima, H. Ushida, Solid State Ionics 70-71 (1994) 267.

[76] F. Giannici, A. Longo, K.-D. Kreuer, A. Balerna, A. Martorana, Dopants and defects: Local structure and dynamics in barium cerates and zirconates (2010).

[77] D. Han, Y. Nose, K. Shinoda, T. Uda, Solid State Ionics 213 (2012) 2. 
[78] D. Han, K. Shinoda, S. Sato, M. Majima, T. Uda, J Mater Chem A 3 (2015) (3) 1243.

[79] D. Han, K. Shinoda, T. Uda, Journal of the American Ceramic Society 97 (2014) (2) 643.

[80] Y. Yamazaki, F. Blanc, Y. Okuyama, L. Buannic, J.C. Lucio-Vega, C.P. Grey, S.M. Haile, Nature Materials 12 (2013) (7) 647.

[81] J.A. Kilner, Solid State Ionics 129 (2000) (1) 13.

[82] G.C. Mather, M.S. Islam, Chem Mater 17 (2005) (7) 1736.

[83] J. Faber, C. Geoffroy, A. Roux, A. Sylvestre, P. Ablard, Appl. Phys. A Applied Physics A Solids and Surfaces 49 (1989) (3) 225.

[84] E. Fabbri, D. Pergolesi, S. Licoccia, E. Traversa, Solid State Ionics 181 (2010) (21) 1043.

[85] R. Glöckner, M.S. Islam, T. Norby, Solid State Ionics 122 (1999) (1) 145.

[86] J. Wu, R.A. Davies, M.S. Islam, S.M. Haile, Chem Mater 17 (2005) (4) 846.

[87] A. Løken, S.W. Saeed, M.N. Getz, L. Xin, T.S. Bjørheim, J Mater Chem A 4 (2016) (23) 9229.

[88] X. Xu, S. Tao, J.T.S. Irvine, J Solid State Chem 183 (2010) (1) 93.

[89] P.-F. Yang, D.-L. Chen, S.-R. Jian, S.-W. Lee, C.-J. Tseng, Procedia Engineering 79 (2014) 599.

[90] G. Ma, T. Shimura, H. Iwahara, Solid State Ionics 110 (1998) (1) 103.

[91] N.V. Sharova, V.P. Gorelov, Russ J Electrochem + 40 (2004) (6) 639.

[92] F. Giannici, A. Longo, A. Balerna, K.-D. Kreuer, A. Martorana, Chem Mater 19 (2007) (23) 5714.

[93] Z. Tao, G. Hou, N. Xu, X. Chen, Q. Zhang, Fuel Cells 14 (2014) (1) 135.

[94] M. Oishi, K. Yashiro, K. Sato, J. Mizusaki, N. Kitamura, K. Amezawa, T. Kawada, Y. Uchimoto, Solid State Ionics 179 (2008) (15) 529.

[95] M.-Y. Wang, L.-G. Qiu, G.-L. Ma, 25 (2007) (9) 1273.

[96] L. Qiu, G. Ma, D. Wen, Solid State Ionics 166 (2004) (1) 69.

[97] D. Han, T. Uda, J Mater Chem A 6 (2018) (38) 18571.

[98] F.M. Draber, C. Ader, J.P. Arnold, S. Eisele, S. Grieshammer, S. Yamaguchi, M. Martin, Nature Materials 19 (2020) (3) 338.

[99] L. Mazzei, A. Perrichon, A. Mancini, L. Malavasi, S.F. Parker, L. Börjesson, M. Karlsson, The Journal of Physical Chemistry C 123 (2019) (43) 26065.

[100] A.K. Baral, Y. Tsur, Journal of the American Ceramic Society 102 (2019) (1) 239.

[101] K.-R. Lee, C.-J. Tseng, S.-C. Jang, J.-C. Lin, K.-W. Wang, J.-K. Chang, T.-C. Chen, S.-W. Lee, International Journal of Hydrogen Energy 44 (2019) (42) 23784.

[102] S. Nikodemski, J. Tong, R. O'Hayre, Solid State Ionics 253 (2013) 201.

[103] D. Gao, R. Guo, Journal of Alloys and Compounds 493 (2010) (1) 288.

[104] C. Duan, R.J. Kee, H. Zhu, C. Karakaya, Y. Chen, S. Ricote, A. Jarry, E.J. Crumlin, D. Hook, R. Braun, N.P. Sullivan, R. O'Hayre, Nature 557 (2018) (7704) 217.

[105] H. An, H.-W. Lee, B.-K. Kim, J.-W. Son, K.J. Yoon, H. Kim, D. Shin, H.-I. Ji, J.-H. Lee, Nat Energy 3 (2018) (10) 870.

[106] K. Toyoura, W. Meng, D. Han, T. Uda, J Mater Chem A 6 (2018) (45) 22721.

[107] D. Han, N. Hatada, T. Uda, Journal of the American Ceramic Society 99 (2016) (11) 3745.

[108] N. Bonanos, Solid State Ionics 53-56 (1992) 967.

[109] N. Bonanos, Solid State Ionics 145 (2001) (1) 265.

[110] S.-J. Song, E.D. Wachsman, S.E. Dorris, U. Balachandran, Solid State Ionics 149 (2002) (1) 1.

[111]M. Oishi, S. Akoshima, K. Yashiro, K. Sato, J. Mizusaki, T. Kawada, Solid State Ionics 179 (2008) (39) 2240 . 
[112] M. Oishi, S. Akoshima, K. Yashiro, K. Sato, T. Kawada, J. Mizusaki, Defect structure analysis of proton-oxide ion mixed conductor BaCe 0.9Nd $0.1 O 3-\delta$ (2010).

[113] R. Kannan, K. Singh, S. Gill, T. Fürstenhaupt, V. Thangadurai, Sci Rep-Uk 3 (2013) 2138.

[114] A. Łącz, Chemical stability of BaCeO3-based materials (2015).

[115] D. Pergolesi, E. Fabbri, A. D’Epifanio, E. Di Bartolomeo, A. Tebano, S. Sanna, S. Licoccia, G. Balestrino, E. Traversa, Nature Materials 9 (2010) 846.

[116] P. Sawant, S. Varma, B.N. Wani, S.R. Bharadwaj, International Journal of Hydrogen Energy 37 (2012) (4) 3848.

[117] P. Babilo, S.M. Haile, Journal of the American Ceramic Society 88 (2005) (9) 2362.

[118] H. Wang, R. Peng, X. Wu, J. Hu, C. Xia, 92 (2009) (11) 2623.

[119] C. Zuo, S.E. Dorris, U. Balachandran, M. Liu, Chem Mater 18 (2006) (19) 4647.

[120] S.W. Tao, J.T.S. Irvine, Advanced materials 18 (2006) (12) 1581.

[121] C.C. Duan, R.J. Kee, H.Y. Zhu, C. Karakaya, Y.C. Chen, S. Ricote, A. Jarry, E.J. Crumlin, D. Hook, R. Braun, N.P. Sullivan, R. O'Hayre, Nature 557 (2018) (7704) 217.

[122] L. Bi, E. Fabbri, Z. Sun, E. Traversa, Solid State Ionics 196 (2011) (1) 59.

[123] Y.-J. Gu, Z.-G. Liu, J.-H. Ouyang, F.-Y. Yan, y. Zhou, Structure and electrical conductivity of BaCe0.85Ln0.15O3- $\delta(L n=G d, Y, Y b)$ ceramics (2013).

[124] E. Fabbri, L. Bi, H. Tanaka, D. Pergolesi, E. Traversa, Adv Funct Mater 21 (2011) (1) 158.

[125] N. Ito, H. Matsumoto, Y. Kawasaki, S. Okada, T. Ishihara, Solid State Ionics 179 (2008) (9) 324.

[126] A.K.E. Andersson, S.M. Selbach, C.S. Knee, T. Grande, Journal of the American Ceramic Society 97 (2014) (8) 2654.

[127] Y.G. Lyagaeva, D.A. Medvedev, A.K. Demin, P. Tsiakaras, O.G. Reznitskikh, Physics of the Solid State 57 (2015) (2) 285.

[128] A. Kruth, J.T.S. Irvine, Solid State Ionics 162-163 (2003) 83.

[129] C. Hiraiwa, D. Han, A. Kuramitsu, A. Kuwabara, H. Takeuchi, M. Majima, T. Uda, Journal of the American Ceramic Society 96 (2013) (3) 879.

[130] I. Ahmed, S.G. Eriksson, E. Ahlberg, C.S. Knee, P. Berastegui, L.G. Johansson, H. Rundlöf, M. Karlsson, A. Matic, L. Börjesson, D. Engberg, Solid State Ionics 177 (2006) (17) 1395.

[131] C. Zhao, Y. Li, W. Zhang, Y. Zheng, X. Lou, B. Yu, J. Chen, Y. Chen, M. Liu, J. Wang, Energ Environ Sci 13 (2020) (1) 53.

[132] R. Lan, J.T.S. Irvine, S. Tao, Sci Rep-Uk 3 (2013) 1145.

[133] J. Kong, A. Lim, C. Yoon, J.H. Jang, H.C. Ham, J. Han, S. Nam, D. Kim, Y.-E. Sung, J. Choi, H.S. Park, ACS Sustainable Chemistry \& Engineering 5 (2017) (11) 10986.

[134] V. Kyriakou, I. Garagounis, A. Vourros, E. Vasileiou, A. Manerbino, W.G. Coors, M. Stoukides, Applied Catalysis B: Environmental 186 (2016) 1.

[135] E. Vasileiou, V. Kyriakou, I. Garagounis, A. Vourros, A. Manerbino, W.G. Coors, M. Stoukides, Solid State Ionics 288 (2016) 357.

[136] A.B. Mhadeshwar, D.G. Vlachos, Catalysis Today 105 (2005) (1) 162.

[137] J. Li, H. Yoon, T.-K. Oh, E.D. Wachsman, Applied Catalysis B: Environmental 92 (2009) (3)

234.

[138] T. Rajesh, R.N. Devi, The Journal of Physical Chemistry C 118 (2014) (36) 20867.

[139] H.D.A.L. Viana, J.T.S. Irvine, Solid State Ionics 178 (2007) (7) 717.

[140] Y. Du, A.S. Nowick, Solid State Ionics Diffusion \& Reactions 91 (1996) (1) 85. 
[141] S. Wang, Y. Chen, S. Fang, L. Zhang, M. Tang, K. An, K.S. Brinkman, F. Chen, Chem Mater 26 (2014) (6) 2021.

[142] I. Yucel, S. Cakmak, Optik 178 (2019) 467.

[143] H. Bouafia, S. Hiadsi, B. Abidri, A. Akriche, L. Ghalouci, B. Sahli, Comp Mater Sci 75 (2013) 1.

[144] S.Q. Fu, W.K. Lee, A.S. Nowick, L.A. Boatner, M.M. Abraham, J Solid State Chem 83 (1989) (2) 221 .

[145] T. Scherban, A.S. Nowick, L.A. Boatner, M.M. Abraham, Applied Physics A 55 (1992) (4) 324.

[146] R. Gonzalez, M.M. Abraham, L.A. Boatner, Y. Chen, The Journal of Chemical Physics 78 (1983) (2) 660 .

[147] R.P. Liferovich, R.H. Mitchell, J Solid State Chem 177 (2004) (6) 2188.

[148] M.R. Levy, B.C.H. Steel, R.W. Grimes, Solid State Ionics 175 (2004) (1) 349.

[149] T.-Y. Chen, K.-Z. Fung, Journal of Power Sources 132 (2004) (1) 1.

[150] Y. Okuyama, T. Kozai, S. Ikeda, M. Matsuka, T. Sakai, H. Matsumoto, Electrochimica Acta 125 (2014) 443.

[151] Y. Okuyama, T. Kozai, T. Sakai, M. Matsuka, H. Matsumoto, Proton transport properties of La0.9M0.1YbO3-delta ( $M=B a, S r, C a, M g)$ (2013).

[152] A.A. Colville, S. Geller, Acta Crystallogr. B 27 (1971) 2311.

[153] S.A. Speakman, J.W. Richardson, B.J. Mitchell, S.T. Misture, Solid State Ionics 149 (2002) (3) 247.

[154] J.B. Goodenough, J.E. Ruiz-Diaz, Y.S. Zhen, Solid State Ionics 44 (1990) (1) 21.

[155] G.B. Zhang, D.M. Smyth, Solid State Ionics 82 (1995) (3) 161.

[156] W. Fischer, G. Reck, T. Schober, Solid State Ionics 116 (1999) (3) 211.

[157] T. Schober, J. Friedrich, F. Krug, Solid State Ionics 99 (1997) (1) 9.

[158] T. Hashimoto, Y. Inagaki, A. Kishi, M. Dokiya, Solid State Ionics 128 (2000) (1) 227.

[159] M. Yoshinaga, M. Yamaguchi, T. Furuya, S. Wang, T. Hashimoto, Solid State Ionics 169 (2004)

(1) 9 .

[160] T. Shimura, T. Yogo, Solid State Ionics 175 (2004) (1) 345.

[161] T.Q. Ta, T. Tsuji, Y. Yamamura, Journal of Alloys and Compounds 408-412 (2006) 253.

[162] T. Hashimoto, M. Yoshinaga, Y. Ueda, K. Komazaki, K. Asaoka, S.J.J.o.t.a. Wang, calorimetry, 69 (2002) (3) 909.

[163] T. Yao, Y. Uchimoto, M. Kinuhata, T. Inagaki, H. Yoshida, Solid State Ionics 132 (2000) (3) 189.

[164] J. Jankovic, D.P. Wilkinson, R. Hui, Journal of Power Sources 201 (2012) 49.

[165] N. Tarasova, I. Animitsa, Journal of Alloys and Compounds 739 (2018) 353.

[166] J. Jankovic, D.P. Wilkinson, R.J.J.o.T.E.S. Hui, 158 (2010) (1) B61.

[167] Y. Du, A.S. Nowick, Solid State Ionics 91 (1996) (1) 85.

[168] M.C. Verbraeken, H.A.L. Viana, P. Wormald, J.T.S. Irvine, Journal of Physics: Condensed Matter 23 (2011) (23) 234111.

[169] K. Oikawa, T. Kamiyama, S. Ikeda, T. Shishido, S. Yamaguchi, Solid State Ionics 154-155 (2002) 641.

[170] Y. Du, A. S. Nowick, Structural Transitions and Proton Conduction in Nonstoichiometric A3B'B "O9 Perovskite-Type Oxides (1995).

[171] Y. Du, A.S. Nowick, MRS Proceedings 369 (1994) 289. 
[172] K. Singh, W.H. Kan, B. Patton, A. Huq, V. Thangadurai, Inorg Chem 57 (2018) (5) 2609.

[173] J.E. Rodrigues, D.M. Bezerra, A. Hernandes, Ordering effect on the electrical properties of stoichiometric Ba3CaNb2O9-based perovskite ceramics (2017).

[174] W.H. Kan, J. Lussier, M. Bieringer, V. Thangadurai, Inorg Chem 53 (2014) (19) 10085.

[175] T.T. Trinh, V. Thangadurai, Electrochimica Acta 56 (2010) (1) 227.

[176] S. Wang, F. Zhao, L. Zhang, K. Brinkman, F. Chen, Journal of Power Sources 196 (2011) (19)

7917.

[177] L.I. Zhijie, R. Liu, Y. Xie, S. Feng, J. Wang, Solid State Ionics 176 (2005) (11) 1063.

[178] IRVINE, T.S. John, CORCORAN, J.D. Derek, LASHTABEG, Anna, WALTON, C. John, Solid State Ionics Diffusion \& Reactions 154 (2002) (154) 447.

[179] CORCORAN, J.D. Derek, IRVINE, T.S. John, Solid State Ionics 145 (2001) (1) 307.

[180] D. Pergolesi, E. Fabbri, A. D’Epifanio, E. Di Bartolomeo, A. Tebano, S. Sanna, S. Licoccia, G. Balestrino, E. Traversa, Nature Materials 9 (2010) (10) 846.

[181] Z. Zhu, E. Guo, Z. Wei, H. Wang, Journal of Power Sources 373 (2018) 132.

[182] S. Fop, K.S. McCombie, E.J. Wildman, J.M.S. Skakle, J.T.S. Irvine, P.A. Connor, C. Savaniu, C. Ritter, A.C. McLaughlin, Nature Materials 19 (2020) (7) 752.

[183] C.C. Duan, J.H. Tong, M. Shang, S. Nikodemski, M. Sanders, S. Ricote, A. Almansoori, R. O'Hayre, Science 349 (2015) (6254) 1321.

[184] E. Fabbri, A. D'Epifanio, E. Bartolomeo, S. Licoccia, E. Traversa, Solid State Ionics 179 (2008) 558.

[185] S. Wang, F. Zhao, L. Zhang, F. Chen, Solid State Ionics 213 (2012) 29.

[186] T. Ishihara, T. Shibayama, M. Honda, H. Nishiguchi, Y. Takita, Journal of The Electrochemical Society 147 (2000) (4) 1332.

[187] V. Esposito, E. Traversa, Journal of the American Ceramic Society 91 (2008) (4) 1037.

[188] A.J. Jacobson, Chem Mater 22 (2010) (3) 660. 